\title{
Nonaqueous Solution Deacidification Treatments to Prolong the Storage Life of Acidic Books: A Review of Mechanistic and Process Aspects
}

\author{
Martin A. Hubbe, ${ }^{\mathrm{a}, *}$ Ute Henniges, ${ }^{\mathrm{b}}$ Antje Potthast, ${ }^{\mathrm{b}}$ Kyujin Ahn, ${ }^{\mathrm{c}}$ and Richard D. Smith ${ }^{\mathrm{d}}$ \\ According to published studies, certain nonaqueous solution-based \\ treatments can be highly effective for prolonging the useful lives of bound \\ volumes, within which the paper had been formed under acidic \\ papermaking conditions. Such treatments, which typically use reactive \\ alkoxide-based organometallic compounds dissolved in low-surface- \\ tension liquids, have been shown to decrease the tendency of the paper \\ to become brittle during long storage or during accelerated aging. This \\ article reviews published evidence concerning the underlying mechanisms \\ of such treatments. Evidence suggests that dissolved alkoxides and \\ related carbonated alkoxide-based compounds are able to react directly \\ with acidic species within acidic paper during treatment of books. Such \\ reactions help explain the demonstrated effectiveness of nonaqueous \\ solution-based deacidification treatments.
}

Keywords: Deacidification of paper and books; Alkoxides; Organometalic compounds; Hydrolysis; Neutralization

Contact information: a: Department of Forest Biomaterials, North Carolina State University, Campus Box 8005, Raleigh, NC 27695-8005 USA; b: University of Natural Resources and Life Sciences, Vienna, (BOKU); Department of Chemistry, Division of Chemistry of Renewables; Muthgasse 18, A-1190 Wien or Konrad-Lorenz-Straße 24, A-3430 Tulln; c: National Archives of Korea, Archival Preservation and Restoration Center; Seongnam-si, Gyeonggi-do, Korea (13449); d: Wei T'o Associates, Inc., 21750 Main Street, Unit 27, Matteson, IL 60443 USA; *Corresponding author: hubbe@ncsu.edu

\section{Contents \\ Introduction . . . . . . . . . . . . . . . 7097 \\ The need for deacidification . . . . 7097 \\ Mechanistic questions . . . . . . . 7098 \\ Criteria for superior performance. . 7098 \\ Established solution-based technol . . 7100 \\ Historical notes . . . . . . . . . . 7101 \\ Chemical aspects . . . . . . . . . . 7102 \\ The alkaline entity . . . . . . . 7102 \\ The nonaqueous solvent . . . . 7104 \\ Procedural aspects ... . . . . . 7106 \\ Selecting the books . . . . . . 7106 \\ Predrying . . . . . . . . . . . 7106 \\ Immersing . . . . . . . . . 7107 \\ Draining . . . . . . . . . . . 7108 \\ Evaporating ........... 7109}

Equilibrating . . . . . . . . . . . 7109

Post-reactions . . . . . . . . 7110

Evidence of effectiveness ..... 7110

Mechanism of deacidification . . . . 7114

Organic-phase reactions . . . . . 7114

Reactions involving moisture . . 7116

Issues of post-moistening . . . 7118

Future outlook \& recommendations 7119

Priority for early treatment . . . 7119

How the treatments work .... 7120

The need for future studies . . . . 7122

Issue for optimization . . . . . . 7123

Conservation treatments . . . . . 7124

Closing comments ......... 7126 


\title{
NOMENCLATURE
}

\author{
Deacidification agents \\ $\mathrm{CME}=$ Carbonated magnesium ethoxylate \\ $\mathrm{CMM}=$ Carbonated magnesium methoxide \\ $\mathrm{CMP}=$ Carbonated magnesium propoxylate \\ DBM = Dibutymagnesium \\ $E M E C=$ Ethoxy magnesium ethylcarbonate \\ $\mathrm{MBTG}=$ Magnesium bis butoxytriglycolate \\ $\mathrm{MMO}=$ Magnesium methoxide, $\mathrm{Mg}\left(\mathrm{OCH}_{3}\right)_{2}$ \\ $\mathrm{MMMC}=$ Methoxymagnesium methylcarbonate \\ Solvents \\ HMDS = hexamethyldisiloxane \\ TCTFE $=$ trichlorotrifluoroethane
}

\section{INTRODUCTION}

At the heart of some of the most successful and important systems for the massdeacidification of books and archival material - to increase their useful lifetimes - is a class of treatments employing organometallic agents dissolved in nonpolar solvents (Hon 1989; Porck 1996; Blüher and Vogelsanger 2001; Cedzova et al. 2006; Ramin et al. 2009; Baty et al. 2010). Such systems have demonstrated high performance in maintaining paper strength when the documents were subsequently subjected to accelerated aging (Brandis 1994; Andres et al. 2008; Ramin et al. 2009; Ahn et al. 2012a; Katuscak et al. 2012; Hubbe et al. 2017). In view of a continuing urgent need to slow down the deterioration of countless books and other paper-based items kept in libraries, archives, museums, and private collections throughout the world, this article reviews published work related to alkoxide-based and related mass deacidification treatments. The goal is to describe the state of the art and to lay a basis for future studies to make additional improvements and to facilitate more widespread implementation of reliable and effective deacidification procedures.

\section{The Need for Deacidification}

A critical need for wide-scale implementation of deacidification treatment for acidic books already has been discussed in earlier articles (Williams 1971; Wilson and Parks 1979; Smith 1987; Baty et al. 2010). Acidity within the pages of books, whether it comes from the acidic conditions under which the paper was produced, from acidic components of the lignocellulosic material, or from air pollution, will catalyze hydrolytic breakdown of the cellulose within the fibers (Smith 1969). In addition to sulfur gases, there is also concern about nitrogen oxides as a major source of air-borne acidity (Badr and Probert 1993; Menart et al. 2014). The paper within books produced between the early 1800s and about 1990 typically was treated with mixtures of rosin size and aluminum sulfate, which is acidic during its formation (Hubbe 2005). The danger is compounded by the fact that hydrolysis leads to the generation of additional acidic compounds within stored books (Calvini et al. 2007; Zervos 2007; Jablonsky et al. 2012). For instance, hydrolysis of acetate esters present in the hemicellulose components of cellulosic fibers will yield 
acetic acid (Polovka et al. 2006). The in situ generated acids accelerate the hydrolytic decomposition.

Oxidation, which is another important mechanism leading to the decomposition of stored books, also tends to be promoted by non-neutral $\mathrm{pH}$ conditions (Arney et al. 1979; Fengel and Wegener 1984). Despite widespread agreement regarding the need for deacidification, there has been a lack of consensus or consistent practice regarding selection and implementation of the treatment options.

Earlier publications by the authors have considered the effectiveness of widely practiced mass deacidification treatments in which no direct neutralization reaction takes place upon introduction of the agent to the acidic books (Hubbe 2015; Hubbe et al. 2017; Potthast and Ahn 2017). The cited publications make the case that treatment of books with suspensions of alkaline particles (such as $\mathrm{MgO}$ ) in nonaqueous solvents tend not to be as effective in neutralization of acidic species present within the paper of the treated books. As a consequence, treatments based on suspensions of alkaline particles tend to be less effective in slowing down the deterioration of acidic books in comparison to certain other treatments in which an alkaline treatment agent is present in dissolved form (Ramin et al. 2009; Katuscak et al. 2012; Hubbe et al. 2017; Potthast and Ahn 2017). The present review article, therefore, will focus on systems in which the alkaline substance is fully soluble in the nonaqueous medium used for deacidification treatment.

\section{Mechanistic Questions Related to Alkoxide-Based Deacidification}

The approach taken in this review article will be to clarify what is known, at a mechanistic level, about each of the steps in an alkoxide-based deacidification process, as revealed by a search of the literature. Despite the demonstrated effectiveness of alkoxidebased nonaqueous treatments, there has been a general lack of attention paid to whether or not the alkaline agent is capable of direct neutralization of acidic species when the books are immersed in the nonaqueous solution. This and other mechanistic questions to be addressed in this article are given in Table 1, together with citations of some relevant publications.

As suggested by the contents of Table 1, a key goal here is to review evidence pertaining to various possible mechanistic descriptions of the alkoxide-based deacidification treatments, with attention to whether or not certain steps in the mechanism are fully or partially realized in typical treatment batches. Emphasis, in this review, will be placed on how and why different treatments work, with less attention paid to which brand of treatment does the best overall job.

\section{Criteria of Superior Performance}

Table 2 lists some of the criteria by which various writers have proposed to judge the success of different mass deacidification processes. The criteria in Table 2 (which can be regarded as a subset of a longer list provided by Hon 1989), provide constraints within which the developers of mass deacidification methods must find workable systems. For instance, there will be constraints on the alkaline agents regarding their having sufficient reactivity and solubility. There will be constraints on the solvents, with the exclusion of those that tend to solubilize inks or hurt the environment, etc. 
Table 1. Mechanistic Questions Concerning the Alkoxide-based Deacidification Treatments

\begin{tabular}{|c|c|c|}
\hline $\begin{array}{l}\text { Category of } \\
\text { Question }\end{array}$ & Mechanistic Question & $\begin{array}{l}\text { Pertinent } \\
\text { Citations, if Any }\end{array}$ \\
\hline \multirow[t]{3}{*}{ Distribution } & $\begin{array}{l}\text { Can the organometallic agent become depleted by } \\
\text { reaction with water before it diffuses all the way into } \\
\text { paper at the typical levels of water content either in the } \\
\text { nonaqueous medium or in the paper that is being } \\
\text { treated? }\end{array}$ & Smith 1977 \\
\hline & $\begin{array}{l}\text { What determines the location and distribution of alkaline } \\
\text { reserve particles left in the paper after solution-based } \\
\text { deacidification treatment? }\end{array}$ & $\begin{array}{l}\text { Smith 1977; Kelly } \\
\text { \& Fowler 1978; } \\
\text { Ramin et al. } 2009\end{array}$ \\
\hline & $\begin{array}{l}\text { What is the particle size distribution, and can it be } \\
\text { controlled by such factors as moisture content? }\end{array}$ & $\begin{array}{l}\text { Eggersdorfer et al. } \\
1990\end{array}$ \\
\hline \multirow{5}{*}{ Reaction } & $\begin{array}{l}\text { Is a reaction of the organometalic agent either with } \\
\text { acidic species or water molecules in the paper required } \\
\text { for the material to be transferred from the nonaqueous } \\
\text { medium to the paper in the course of treatment? }\end{array}$ & - \\
\hline & $\begin{array}{l}\text { Does the organic agent react with water present in the } \\
\text { paper during the treatment period? After that period? }\end{array}$ & $\begin{array}{l}\text { Kelly et al. } 1977 \\
\text { Clark et al. } 1998\end{array}$ \\
\hline & $\begin{array}{l}\text { Does the organometallic agent react efficiently with } \\
\text { organic acids (e.g. formic, acetic acids) in the paper } \\
\text { during the immersion step in a nonaqueous treatment? }\end{array}$ & $\begin{array}{l}\text { Kickelbick et al. } \\
\text { 2002; Turbova et } \\
\text { al. } 2002\end{array}$ \\
\hline & $\begin{array}{l}\text { Does the organometallic agent react efficiently with } \\
\text { inorganic acids in the paper, noting that in aqueous } \\
\text { systems such acids would be in an ionized form before } \\
\text { such neutralization reactions (e.g. sulfuric acid)? }\end{array}$ & $\begin{array}{l}\text { Henniges et al. } \\
2012\end{array}$ \\
\hline & $\begin{array}{l}\text { Following a typical nonaqueous solution-based } \\
\text { deacidification, do certain kinds of acid species (perhaps } \\
\text { inorganic species such as acidic aluminum compounds } \\
\text { or sulfuric acid) remain in the paper? }\end{array}$ & $\begin{array}{l}\text { Hon 1989; } \\
\text { Clark et al. 1998; } \\
\text { Hubbe } 2005\end{array}$ \\
\hline \multirow[t]{2}{*}{ Completion } & $\begin{array}{l}\text { By optimizing the moisture content of the paper or by } \\
\text { equilibration of the treated paper with humid air, can one } \\
\text { ensure that most or all of the organometallic agent gets } \\
\text { converted to the hydroxide, oxide, or carbonate form } \\
\text { during the course of the treatment? }\end{array}$ & $\begin{array}{l}\text { Hon 1989; Brandis } \\
\text { 1994; Wittekind } \\
\text { 1994a; Blüher and } \\
\text { Vogelsanger } 2001\end{array}$ \\
\hline & $\begin{array}{l}\text { By optimizing the level of organometallic agent, at a } \\
\text { given moisture content, can one ensure that accessible } \\
\text { acidic groups within the structure are neutralized during } \\
\text { the course of the treatment? }\end{array}$ & - \\
\hline \multirow{3}{*}{$\begin{array}{l}\text { Chemistry- } \\
\text { related issues }\end{array}$} & $\begin{array}{l}\text { Is there an ideal range of reactivity for an organometallic } \\
\text { deacidification agent to be applied as a solution? }\end{array}$ & Kelly et al. 1977 \\
\hline & $\begin{array}{l}\text { What is achieved by carbonation of an alkoxide before it } \\
\text { is used in deacidification? By rendering the agent less } \\
\text { reactive with water, does it also become less able to } \\
\text { react with acidic species in the paper? }\end{array}$ & Kelly et al. 1977 \\
\hline & $\begin{array}{l}\text { What is the best mechanistic explanation for the } \\
\text { advantage of combining two different commercially used } \\
\text { alkoxide chemistries (MMMC and double alkoxide)? }\end{array}$ & Smith 2013 \\
\hline
\end{tabular}


Though there probably will continue to be improvements in deacidification systems in the coming years, there is much evidence that the established nonaqueous solution-based deacidification technologies have generally performed well in meeting the expectations represented in Table 2, whereas the "why" and "how" questions mentioned in the previous table are in particular need of attention.

Table 2. Criteria to Judge Success of Mass Deacidification Methods

\begin{tabular}{|c|c|}
\hline Criteria & Selected citations \\
\hline Reliable neutralization of the acidic groups & Schwerdt 1989; Cedzova et al. 2006 \\
\hline Pervasive infusion of agent into nano-scale spaces & $\begin{array}{l}\text { Ramin et al. 2009; Potthast \& Ahn } \\
\text { 2017; Hubbe et al. } 2017\end{array}$ \\
\hline Sufficient alkaline reserve deposited uniformly & Schwerdt 1989; Ahn et al. 2012b \\
\hline Lack of grit or visible solids & Kelly \& Fowler 1978; Hon 1989 \\
\hline Lack of effects involving inks or dyes & Lienardy 1994 \\
\hline Avoidance of distortion of paper, cover, or bindings & Hon 1989; Schwerdt 1989 \\
\hline Does not harm the natural environment & Hon 1989; Schwerdt 1989 \\
\hline Safe both during treatment and when in the books & $\begin{array}{l}\text { Hon 1989; Schwerdt 1989; Wittekind } \\
\text { 1994a; Blüher \& Vogelsanger } 2001\end{array}$ \\
\hline $\begin{array}{l}\text { Extended lifetime, as demonstrated by accelerated } \\
\text { aging tests, after application of the deacidification }\end{array}$ & $\begin{array}{l}\text { ISO/TS } 18344 \text { 2016; Burgess \& } \\
\text { Kaminska 1991; Kaminska \& Burgess } \\
\text { 1994; Porck 1996 }\end{array}$ \\
\hline
\end{tabular}

Conservation treatment options when using nonaqueous solutions

In addition to the criteria that can be regarded as essential to achieving deacidification, some authors have specified that an ideal mass deacidification treatment also ought to address other paper characteristics, such as strength, resistance to mold, and washing away contaminants (Daniels 1996; Andres 2006; Baty et al. 2010). Among these characteristics, the improvement of paper strength seems to pose the most daunting challenges within the constraint of purely nonaqueous treatments. Conventional means of imparting strength to paper generally involve the use of water (Daniels 1996; Sundholm and Tahvanainen 2003; Hubbe 2006). Though nonaqueous treatments to achieve strength improvements in existing paper documents have been demonstrated (Smith 1972a, 1987; De Leeuw 1988a,b; Porck 1996; Wittekind 1996; Ipert et al. 2006; Dupont et al. 2010; Smith 2012, 2013), they do not appear to have received sufficient attention; so a section late in this article will focus on such treatments.

\section{ESTABLISHED NONAQUEOUS SOLUTION-BASED TECHNOLOGIES}

Commercially-demonstrated, solution-based nonaqueous deacidification practices will be introduced here, starting with a historical overview, then considering chemical aspects (focusing on the alkaline reagent and the solvent), then the procedural steps. Broad descriptions of the technology are given in the following sources (Smith 1987; Morrow 1988; Hon 1989; Schwerdt 1989; Blüher and Vogelsanger 2001; Baty et al. 2010; Ahn et al. 2012a). 


\section{Historical Notes}

The motivation for development of organometallic solution-based deacidification processes can be traced to the cost and difficulty of applying the classical aqueous-based deacidification procedures (Smith 1979; Wittekind 1994a) in the case of bound books. Though aqueous solutions of bicarbonate compounds are still widely used for deacidification of single sheets of paper, problems would be encountered if such treatments were to be applied to bound volumes.

Certain inks and dyes used in books may partly dissolve, leaving smears and stains (Lienardy 1994; Banik and Brückle 2011). The pages swell and become thicker when wet, often enough to break the binding of a book (Smith 1992; Kellerman 1999). Drying of a bound book, after its immersion in water, can result in wavy pages (Brückle and Banik 2011b).

According to Hon (1989), as early as 1891 a nonaqueous solvent, methanol, was being using by the British Library to distribute an alkaline compound $\left(\mathrm{Ba}(\mathrm{OH})_{2}\right)$ within paper to extend its lifetime. Methanol is not an ideal liquid for such purposes, since it has been found to solubilize some ink components. Since $\mathrm{Ba}(\mathrm{OH})_{2}$ does not form a true solution in methanol, the system would not fully qualify as a "solution-based nonaqueous" treatment, which will be our main focus.

Starting in the 1960s, such problems were addressed in the pioneering work of Baynes-Cope (1969) and Smith (1970; 1972b; 1979), who surmised that effective deacidification of whole books could be achieved with a system comprising the following components:

a) A nonpolar organic solvent, having a low surface tension, no tendency to swell the pages of books, and little affinity for inks and colorants likely to be present in paper documents; a suitable low surface tension also ensures a favorable contact angle for quick wetting and permeation into capillary spaces within the paper and within fibers.

b) An alkaline agent that is fully soluble in the carrier fluid, making it possible to distribute it throughout bound documents, including the fine pores of paper and the less-accessible spine area of pages in a book

c) Evaporation of the carrier fluid, thus leaving behind the precipitated alkaline particles, any unreacted deacidification agent, and presumed completion of the neutralization of acidic chemical species that had been present within the paper

d) Reaction of the deacidification agent with trace residual water within the dry paper, and also with moisture added during atmospheric conditioning of the treated paper, so that a suitable amount of insoluble particles of "alkaline reserve matter" of suitably small size becomes precipitated within the paper

Though there have been many subsequent developments in related processes, following the cited works by Baynes-Cope and Smith, the basic concept outlined above has continued to serve as the basis for the commercial systems (and versions of systems) that are outlined in Table 3. 
Table 3. Historical Developments in Alkoxide-based Deacidification Treatments with Nonaqueous Solvents

\begin{tabular}{|c|c|c|c|}
\hline System & Carrier liquid & Alkaline agent & Citation(s) \\
\hline 1891 process & Methanol & $\mathrm{Ba}(\mathrm{OH})_{2}$ & Hon 1989 (Sir Arthur Church) \\
\hline 1961 tests & Solvent unspecified & Mg methoxide (MMO) & Baynes-Cope 1969 \\
\hline Smith thesis & Freon & MMO & Smith 1970 \\
\hline Wei T'o original & Chlorofluorocarbon & $\mathrm{MMO}$ & Smith $1972 b$ \\
\hline Wei T'o 1976 & Chlorofluorocarbon & MMMC & Kelly 1976; Smith 1979 \\
\hline Wei T'o option & TCTFE & Mix MMMC \& MMO & Smith 1977 \\
\hline FMC & Hydrocarbon & Alkoxyalkoxides * & Kaminsky \& Wedinger 1992 \\
\hline FMC & Hydrocarbon & MBTG, DBM & Wedinger 1993 \\
\hline Battelle & Solvent unspecified & Ti and $\mathrm{Mg}$ alkoxides & Wittekind et al. 1994 \\
\hline Battelle & HMDS & MMMC & Wittekind 1994b, 1996 \\
\hline Hüls AG & Ethanol or methanol & CME, CMM & Raulender et al. 1995a,b \\
\hline British library & Solvent unspecified & EMEC & Worsfold 1996; Clark et al. 1998 \\
\hline $\begin{array}{l}\text { CSC } \\
\text { Booksaver }\end{array}$ & $\begin{array}{l}\text { Propanol/ } \\
\text { heptafluoropentane } \\
\text { (solvent HFC 227) }\end{array}$ & $\begin{array}{l}\text { Carbonated } \\
\text { magnesium } \\
\text { propoxylate (CMP) }\end{array}$ & $\begin{array}{l}\text { Dupont et al. } 2002 \text {; Gibert } \\
\text { Vives et al. 2004; Henniges et } \\
\text { al. 2005; Wagner et al. } 2008\end{array}$ \\
\hline $\begin{array}{l}\text { Univ. Evry \& } \\
\text { Museum Nat. } \\
\text { History, Paris }\end{array}$ & HMDS & $\begin{array}{l}\text { Aminopropylmethyl } \\
\text { diethoxysilane }\end{array}$ & $\begin{array}{l}\text { Ipert et al. 2006; Dupont et al. } \\
\text { 2010; Souguir et al. 2011, 2012; } \\
\text { Piovesan et al. 2014, 2017 }\end{array}$ \\
\hline Wei T'o option & Chlorofluorocarbon & MMO, Ti\&Mg alkoxides & Smith 2012, 2013 \\
\hline
\end{tabular}

Notes: $\mathrm{HMDS}=$ hexamethyldisiloxane; $\mathrm{MMO}=$ magnesium methoxide; $\mathrm{MMMC}=$ methoxymagnesium methylcarbonate; TCTFE = trichlorotrifluoroethane; $\mathrm{MBTG}=$ magnesium bis butoxytriglycolate; $\mathrm{DBM}=$ dibutymagnesium; ${ }^{*}=$ optionally treated with $\mathrm{CO}_{2} ; \mathrm{CME}=$ carbonated magnesium ethylate; $\mathrm{CMM}=$ carbonated magnesium methoxide; $\mathrm{CMP}=$ carbonated magnesium propoxylate; EMEC = ethoxy magnesium ethylcarbonate

To reinforce the point that relatively low surface tension liquids have been used, whereas pure water has a surface tension of about $72 \mathrm{mNm}^{-1}$ at room temperature, the other liquids listed in Table 3 generally have much lower values (e.g. HMDS $15.6 \mathrm{mNm}^{-1}$; heptafluoropentane $15.1 \mathrm{mNm}^{-1}$ ).

\section{Chemical Aspects}

The alkaline entity

As can be seen from entries in the third column of Table 3, several different reactive alkaline species, each dissolved in a nonaqueous solvent, have been used for mass deacidification. In particular, the Wei-T'o system, using methoxymagnesium methylcarbonate (MMMC) dissolved in chlorofluorocarbon solvent with approximately 5\% methanol content, was used during the period from 1974 to 1995 at the National Library of Canada (Smith 1979; Scott 1987; Morrow 1988; Porck 1996). A related system from Battelle, using a mixture of titanium ethoxide and magnesium ethoxide dissolved in hexamethyldisiloxane has been in use in Germany and Switzerland since the 1990s (Wittekind 1994). Furthermore, a French process developed by the Biblioteque Nationale de France, based in Sablé, was derived from the Wei T'o process. The CSC Booksaver system, employing carbonated methyl propoxylate (CMP) in a propanol-fluorocarbon solvent mixture, became available in 2002 (Dupont et al. 2002; Gibert Vives et al. 2004; Wagner et al. 2008; Henniges et al. 2012). Notably, all of the major alkaline agents used in nonaqueous solution deacidification systems have been based on metal alkoxides - 
either in their simple form or after stabilizing them by reaction with carbon dioxide. In simple terms, the metal alkoxide family of reagents appears to offer species with suitable solubility in low-surface-tension carrier fluids as well as suitable levels of reactivity.

Magnesium methoxide: The formula for $\mathrm{MMO}$ can be expressed as $\mathrm{Mg}\left(\mathrm{OCH}_{3}\right)_{2}$. As was already noted by Baynes-Cope (1969), magnesium methoxide is highly reactive with water - both in solution and in humid air. The high reactivity of MMO with water discouraged the cited author from considering it further after carrying out some initial tests, which nevertheless showed the reagent to be effective for deacidification. Smith (1970, 1972b) developed a workable deacidification system with magnesium methoxide by use of a combination of very dry solvent and by vacuum-drying of books prior to the treatment.

Methoxymagnesium methylcarbonate: Kelly (1976), working under contract to the US Library of Congress, was the first to employ MMMC for deacidification. The compound, which was reported to have the formula $\mathrm{H}_{3} \mathrm{COMgOCOOCH}_{3}$, already had been described by Finkbeiner and Stiles (1963) as being a more stable compound, while still retaining essential features of an alkoxide. MMMC can be prepared by bubbling $\mathrm{CO}_{2}$ gas through a solution of MMO (Finkbeiner and Stiles 1963; Kelly et al. 1977; Wedinger 1993; Jaegers et al. 1994; Daniels 1996), as represented by Eq 1.

$$
\mathrm{H}_{3} \mathrm{CO}-\mathrm{Mg}-\mathrm{OCH}_{3}+\mathrm{CO}_{2} \rightarrow \mathrm{H}_{3} \mathrm{CO}^{-\mathrm{Mg}_{\cdot} \mathrm{O}} \stackrel{\stackrel{\mathrm{O}}{\mathrm{N}}}{\mathrm{OCH}_{3}}
$$

Smith (1977) described one option in which the MMMC is initially dissolved in methanol, contributing to its stability and facilitating solubilization in a chlorofluorocarbon solvent.

Carbonated magnesium propoxylate: The validity of the chemical structure shown in Eq. 1 might be questioned based on more recent analysis by Henniges et al. (2005), who studied the treatment conditions corresponding to the CSC Booksaver process (Dupont et al. 2002; Gibert Vives et al. 2004; Henniges et al. 2005; Wagner et al. 2008). The treatment agent in that process has been called "carbonated alcoholate," and it was shown to be effective in terms of paper's $\mathrm{pH}$ and resistance to aging (Dupont et al. 2002; Gibert Vives et al. 2004; Henniges et al. 2005; Wagner et al. 2008). The ethyl version of such chemistry was claimed by Rauleder et al. (1995a,b).

The actual structure of the reagent (named carbonated magnesium propoxylate or carbonated magnesium propylate) was elucidated by Henniges et al. (2005) and is given in Eq. 2.

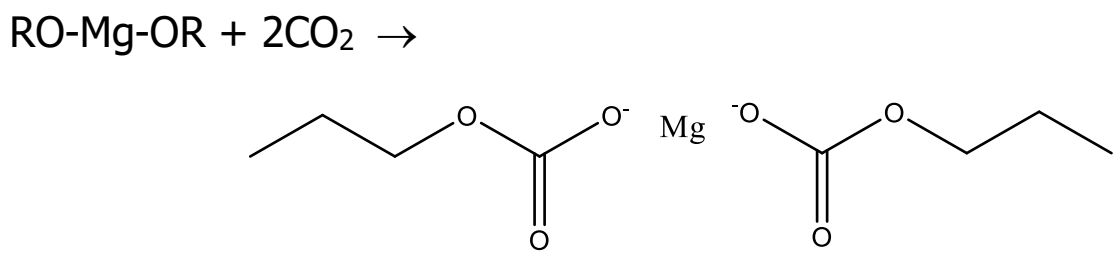

Because the preparation conditions used in the CSC Booksaver process are not radically different from those used in earlier work related to MMMC (Finkbeiner and Stiles 1963; 
Kelly et al. 1977; Wedinger 1993; Jaegers et al. 1994; Daniels 1996), it is difficult to conclude that the reaction to form MMMC stops at the point represented by Eq. 1. Logic would suggest that the reaction of the magnesium methoxide might also be able to involve two moles of carbon dioxide, providing a product analogous to what is shown in Eq. 2 for the isopropoxide.

Double alkoxide, Mg ethoxide, and Ti ethoxide: The Battelle process (Papersave and Papersave Swiss, which are respectively provided by Zentrum fur Bucherhaltung Leipzig and Nitrochemie AG, Switzerland and Germany) employs a so-called "double alkoxide" (Meerwein and Bersin 1929). The formula has been published as $\mathrm{Me}_{1}(\mathrm{OR})_{4} \cdot \mathrm{Me}_{2}(\mathrm{OR})_{2}$ (Wittekind 1994a,b), where the first metal, in the actual composition employed, is Ti, the second is $\mathrm{Mg}$, and $\mathrm{R}$ is the ethyl group. Despite this description, it appears that the double alkoxide is actually just a mixture of the two alkoxides (Porck 1996). The principal reason for including the titanium ethoxide may be to help solubilize the magnesium ethoxide in a low-energy (siloxane) solvent. Wittekind (1994a) states that the conversion of $\mathrm{Ti}\left(\mathrm{OCH}_{2} \mathrm{CH}_{3}\right)_{4}$ to $\mathrm{TiO}_{2}$ helps to strengthen the paper, but the evidence in this regard is unclear (Porck 1996). The ethoxyl, rather than the methoxyl group in the double alkoxide was selected in order that the product of reactions would be ethanol rather than methanol, which can be a health hazard (Pronha 2016). According to Andres et al. (2008), the mixture also contains some titanium propoxide.

Combined double alkoxide and MMMC: More recently Smith $(2012,2013)$ discovered an advantage of combining the Ti/Mg ethoxide mixture with methoxymagnesium methyl carbonate for deacidification. The combination was found to achieve high retention of alkaline reserve material in the paper without producing a gritty feel or uneven distribution of the deposited material. Smith (2013) hypothesized that the MMMC forms a tacky gel in the course of solvent evaporation and that fibrils of the gel entrap particles formed during precipitation of particles from the double alkoxide component.

\section{The nonaqueous solvent}

The ideal solvent for nonaqueous solution-based deacidification would be cheap, non-toxic, non-flammable, sufficiently low in polarity to avoid solubilization of ink, but on the other hand having sufficient interaction energy to effectively solubilize the selected alkoxide-based reagent or reagents.

Methanol: Methanol has a long history of use, starting in the late 1800s in the British Library (Kelly and Fowler 1978; Hon 1989). Smith describes using methanol as a minor cosolvent, presumably to aid in the mixing and stability of solutions containing MMMC in chorofluorocarbon solvents. Methanol in the Wei T'o system was kept to no more than $5 \%$ during treatments to minimize solubilization of inks. On the other hand, methanol or another alcohol was claimed in the patent for a system for convenient spray for deacidification of single pages (Smith 1989). Caution is required in light of the known toxicity of methanol (Tephly 1991; Pronha 2016).

Chlorofluorocarbons: In his initial work, Smith $(1970,1972 b)$ used perfluorinated or chlorofluoro hydrocarbons as the main solvent for the alkoxide. HFC-134 $(1,1,1,2-$ 
tetrafluoroethane) was later used in the Wei T'o system because it was found to be a good solvent for MMMC (Smith 2013). Hydrofluorocarbons have been specified as solvents or carriers for various deacidification systems (Leiner and Kifer 1995; Blüher and Vogelsanger 2001; Thomas and Diggs 2003; Banik 2005). Due to a concern about potential ozone depletion, specified chlorofluorocarbons have been used in place of earlier used versions of chlorofluorinated solvents for such systems (Smith 1977, 1982; Green and Leese 1991; Clark et al. 1998). Hon (1989) states that a mixture of Freon 12 (dichlorodifluoromethane) and 113 (1,1,2-trichloro-1,2,2-trifluoroethane) has been used in the Wei T'o system. Propanol and heptafluoropentane (HFC 221) are used in the CSC Booksaver process in combination with carbonated magnesium propoxylate. Though certain highly fluorinated compounds have been implicated in damage to the stratospheric ozone layer (Solomon 1999), it also has been found that the specific structure of such compounds is critically important. For example, the $\mathrm{CF}_{3}$ group in hydrofluorocarbons has been found to have a negligible contribution to ozone depletion (Ravishankara et al. 1994). A hydrofluorocarbon, HFC-227 (1,1,1,2,3,3,3-heptafluoropropane) is another option that offers the positive attributes of non-flammability and benign behavior with respect to atmospheric ozone. According to Couture (1999), the HFC solvents were found to provide excellent stability of the alkoxide-based reagent using the Wei T'o system. Nevertheless, some authors have asserted that chlorofluorocarbons are not to be regarded as a long-term option (Kelly et al. 1977; Blüher and Vogelsanger 2001). Schwerdt (1989) stated that there was too much loss of such solvent when operating the Sable process, a French system described as being similar to Wei T'o. Hexamethylenedsiloxane and related chemicals are regarded as more environmentally friendly than the chlorofluorinated solvents (Blüher and Vogelsanger 2001).

Silane-based solvents: Hexamethyldisiloxane (HMDS) has been adopted as the solvent for solution-based mass deacidification that is currently being carried out by the Battelle process by Zentrum fur Bucherhaltung Leipzig and Nitrochemie Wimmis AG, Switzerland and Germany (Wittekind 1994a,b; Porck 1996; Banik 2005; Hubbe et al. 2017). Wittekind (1994a) described this solvent as having nearly ideal properties, with the exception of its being flammable. Also, HMDS is regarded as an environmental hazard and thought to be also carcinogenic, a mutagen, and toxic to reproduction (Greve et al. 2008; Wang et al. 2013). As was noted earlier, it appears that titanium ethoxide, which is part of the reactive agent, also functions as a co-solvent to help solubilize the magnesium ethoxide in the formulation. Silanes and siloxanes are also mentioned as solvents in other patents and articles dealing with deacidification of books (Clark et al. 1998; Smith 2000).

Heptane: Porck (1996) noted that FMC initially used chlorofluorocarbon solvent in their mass deacidification system, but they subsequently switched to heptane. Although heptane is flammable, such compounds are relatively cheap. Health concerns related to aliphatic and especially aromatic hydrocarbons have been reviewed by Ravindra et al. (2008). Thus, it would be interesting to know more about whether heptane and similar solvents are capable of solubilizing widely-used alkoxide-based chemicals such as MMMC and the extent to which they affect common inks in books. 


\section{Procedural Aspects}

Though the details of solvent-based nonaqueous deacidification technologies differ to some extent, it is still possible to envision a series of steps that are generally common to all such procedures. These steps are shown in Fig. 1. The discussion that follows will follow the chronological order of such steps.

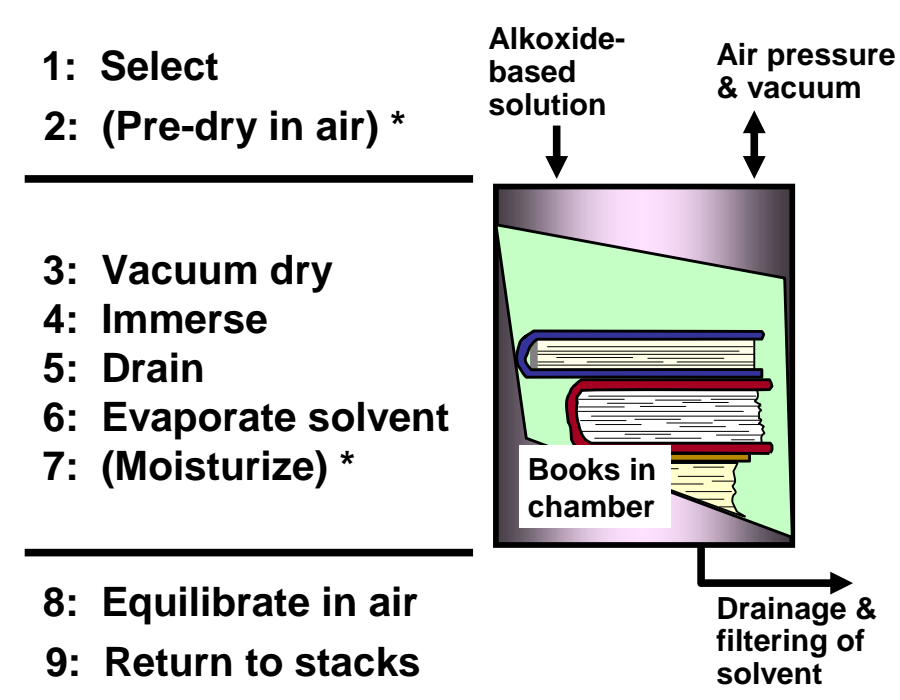

Fig. 1. Sequence of established and possible optional steps in a typical nonaqueous solutionbased deacidification system. "*" = non-standard step, as discussed.

\section{Selecting the books}

Selecting of appropriate books for deacidification is often listed as the first step in a mass deacidification process (Smith 1979; Scott 1987; Hon 1989; Ahn et al. 2011). Books to exclude from such a process would generally include items printed on alkaline paper, coated papers, items so unique and precious that they ought to be individually treated, or items too big to fit into the equipment. Items including unusual inks or colorants, if known, might also be excluded. Books that are already in bad condition don't significantly benefit from the treatment and in addition suffer from the handling process. Because the Wei T'o process requires drying of books down to about $0.5 \%$ moisture content or below, it has been recommended to exclude books with leather covers, which might be adversely affected by severe drying, as well has by alkaline conditions (Scott 1987; Hon 1989). Plastic covers are also prone to cause trouble, as they might interact with the solvents used or the alcohols formed from the alkoxides in the course of the deacidification treatment.

\section{Pre-drying}

The next step is to pre-dry the books (Smith 1979). In the Wei T'o system the books are gently warmed overnight, and then vacuum is applied to achieve a moisture content of about $0.5 \%$ (Brandis 1994). According to Scott (1987), the National Library of Canada dried books for $36 \mathrm{~h}$ under vacuum. A vacuum level of 50 torr has been used (Smith 2012). In the Battelle system the books are dried under vacuum to a moisture content of less than 1\% (Wittekind 1994a; Clark et al. 1998; Blüher and Vogelsanger 
2001). Clark et al. (1998) noted that books were not pre-dried in a related system used by the British Library, and they attributed "clumping" of the alkaline material to the relatively high moisture content. The Battelle process initially involved microwave heating, as a means to speed up the vacuum drying (Eggersdorfer et al. 1990; Liers and Schwerdt 1995), but that approach was later abandoned due to scorching in cases where staples, wires, or other metal items were present in the books (Porck 1996). According to Smith (1977), preliminary removal of most of the water from a book permits a more uniform distribution of the deacidification medium and reduces contamination of the excess liquid formulation that is returned to the storage tank.

It should be noted that the CSC Booksaver process does not entail the pre-drying of books, though they are frozen prior to addition to the reactor. The fact that skipping of the pre-drying step is feasible with CSC Booksaver might be attributed to the decreased water-reactivity of the fully carbonated alkoxide reagent CMP (Henniges et al. 2012).

\section{Immersing}

The deacidification solutions, as listed in Table 3, generally can be described as water-free. Smith (2013) specifies a moisture content of no more than $100 \mathrm{ppm}$ in the solvent, and ideally not more than $5 \mathrm{ppm}$.

The major commercial systems for solution-based nonaqueous mass deacidification have been carried out by placing closed books in an immersion chamber, e.g. in the manner illustrated in Fig. 1. To facilitate relatively rapid infusion of fluid into the paper, the material is subjected to combinations of vacuum and pressure. For example, in the Wei T'o process, the chamber is first evacuated, then filled with the treatment solution, then subjected to pressure. The initial negative pressure within the pages of books not only aids in pulling the liquid inwards, between the pages and within the paper, but it also avoids any blocking effects that could be caused by the presence of bubbles or air-filled pores.

In the Wei T'o system an applied hydrostatic pressure of up to $100 \mathrm{psi}(690 \mathrm{kPa})$ is used to ensure prompt and complete wetting of even the small and remote pores within a book (Smith 2012). As noted by Smith (1979) the books are completely flooded and soaking wet all the way through. Brandis (1994) describes a 50-minute immersion period for the Wei T'o process. However, an immersion period of 5 to 10 minutes is specified in the most recent technological systems from Wei T'o (Smith 2013). A relatively longer time, two to three hours of the immersion procedure has been reported for the Papersave Swiss (Reist 2006). In the Battelle system, no elevated pressure is described (Wächter et al. 1998; Blüher and Vogelsanger 2001). Eggersdorfer et al. (1990) describe a process in which the initial negative pressure within the vacuum-treated books helps to draw the treatment solution into the internal spaces.

\section{Reacting initially}

Published sources have been quite silent regarding whether or not neutralization reactions occur directly with acidic species within the paper during the immersion period. This might mean that nobody has questioned whether or not such reactions occur, or it might mean that those involved with the technology have focused on other issues. Also, it is reasonable to question whether such reactions become completed during an immersion step, or whether they become completed when the paper has been exposed to higher humidity, such as during equilibration of the books with humid air after the treatment. 
Blüher and Vogelsanger (2001) proposed that the following reaction can take place between magnesium ethoxide and sulfuric acid present within paper.

$$
\mathrm{Mg}\left(\mathrm{OC}_{2} \mathrm{H}_{5}\right)_{2}+\mathrm{H}_{2} \mathrm{SO}_{4} \rightarrow \mathrm{Mg} \mathrm{SO}_{4}+2 \mathrm{C}_{2} \mathrm{H}_{5} \mathrm{OH}
$$

Blüher and Vogelsanger (2001) further proposed that $\mathrm{Mg}(\mathrm{OH})_{2}$ formed by reaction between $\mathrm{Mg}\left(\mathrm{OC}_{2} \mathrm{H}_{5}\right)_{2}$ and water present in the paper can react with $\mathrm{CO}_{2}$ in the air to give magnesium carbonate or mixed carbonate-hydroxide species. Such a reaction might take place when paper is allowed to equilibrate with ordinary humid air. However, reactions of $\mathrm{H}_{2} \mathrm{SO}_{4}$ typically involve dissociation into ionic species prior to reaction, and it has not been shown whether or not the reactions shown in Eq. 3 would take place in nonaqueous media to be completed during a typical non-aqueous treatment. Another alternative is that the strong acids such as $\mathrm{H}_{2} \mathrm{SO}_{4}$ may be able to exchange with the conjugate bases of weak acid species within the paper, e.g. formate and acetate, such that the protonated forms of formic acid, acetic acid, etc., are in the paper and the sulfuric acid would mainly have been converted to sulfate. Evidence related to reactions between alkoxide-related compounds and carboxylic acids will be considered later in this article.

As noted by Clark et al. (1998), alkoxide-related agents can be expected to react with any water present, leading to the formation of the corresponding hydroxides. Loss of water, which is more likely to happen later during a drying treatment or during storage, could result in the formation of the corresponding metal oxide (Eggersdorfer et al. 1990; Wittekind 1994a; Boyle 1999; Stengl et al. 2003; Khairallah and Glisenti 2007). Reaction of the hydroxide with carbon dioxide, as normally present in air, would give rise to the carbonate or possibly to bicarbonate species (Kelly et al. 1977; Hon 1989; Green and Leese 1991; Clark et al. 1998).

Methoxy magnesium methyl carbonate (MMMC) offers a potential advantage for purposes of deacidification because the product of its reaction with water is already in the form of magnesium carbonate. Kelly et al. (1977) proposed the following reaction:

$$
\mathrm{CH}_{3} \mathrm{OMgOCO} 2 \mathrm{CH}_{3}+\mathrm{H}_{2} \mathrm{O} \rightarrow \mathrm{MgCO}_{3}+2 \mathrm{CH}_{3} \mathrm{OH}
$$

In support of this proposed reaction, the cited authors reported that acidic paper that had been freshly deacidified with MMMC induced bubbling when droplets of acid were placed on it. By contrast, no such effervescence was observed until two days after deacidification carried out with magnesium methoxide.

\section{Draining}

The next step after immersion is to drain away the excess liquid (Smith 1979; Eggersdorfer et al. 1990; Blüher and Vogelsanger 2001; Smith 2013). When one considers the central role of draining, as a way to remove most of the solvent from the treated items, it is remarkable that none of the published articles or patents provides any details about this step. Presumably, if a puddle of liquid were to remain between two pages of a book when evaporation is taking place, then the reagent and/or alkaline reserve particles present in that liquid would tend to land haphazardly onto the adjacent paper surfaces during the subsequent evaporation of the solvent. No study was found that gives any information about effects of such variables as the orientation of the books, or the time duration, and the results of the drainage step. It is clear, however, that precipitated solids at least sometimes accumulate in the nonaqueous solvent during the immersion step (Kelly et al. 1977; Smith 
1979; Hon 1989; Raulender 1995b; Smith 2013). For example, Eggersdorfer et al. (1990) describe the use of a fine filter to remove "mud particles," e.g. magnesium oxide or hydroxide, from the nonaqueous solvent after the immersion step. It is logical to expect such solids to accumulate at locations where evaporation is taking place.

\section{Evaporating}

Vacuum is used again, after the treatment, to flash off the solvent and leave behind the less volatile (or already reacted) alkaline agent (Smith 1979; Scott 1987; Brandis 1994; Blüher and Vogelsanger 2001; Smith 2012, 2013). Smith (1979) described the process as "flash drying," which was completed within a few minutes. Smith (1977) and Kelly and Fowler (1978) noted that there can be a tendency for liquid to flow toward the edges of a book, where evaporation may be taking place rapidly, leading to low local temperatures. Uneven distribution of alkaline reserve material was said to be a consequence of such a process. More even distribution can be achieved by application of gentle heat during the evaporation stage or by using a lower differential vacuum (Smith 1977). Couture (1999) describes increasing efficiency of recovery of solvent achieved with the prototype Wei T'o system, eventually reaching 93.5\% during operation in Canada from 1991 to 1998. In principle, very high levels of solvent recovery can be expected when using state-of-the-art equipment and procedures.

Wächter et al. (1998) described an analogous vacuum system for evaporating water from books that had been deacidified using aqueous media; a key difference was that the books were allowed to freeze, and the water was removed under vacuum while the books were still in the frozen condition. Such practices provide options for nonaqueous treatments, since similar equipment and conditions can be used.

\section{Equilibrating with humid air}

In the case of established mass deacidification systems, after evaporation of the solvent, the treated books are exposed to warm ambient air (Smith 1979; Scott 1987). Smith (1977) specified a moisture content of 1 to $2 \mathrm{ppm}$ in the air used for equilibration. Smith (1979) and Brandis (1994) describe "overnight" equilibration to regain typical moisture content in the Wei T'o-treated books. According to Scott (1987) books treated by the Wei T'o system in Canada were returned to their stack in a week, following a treatment cycle of about one hour. In the case of the Battelle system, Blüher and Vogelsanger (2001) report a 3 to 4 week equilibration with air of specified relative humidity blown through the space containing the books.

Though it is not part of any past or currently used mass deacidification system, a patent by Smith (2013) claimed the concept of exposing the system to high humidity after the immersion and solvent evaporation steps. The motivation to take such a step could be to allow any remaining Brønsted acid species in the paper (e.g. $\mathrm{RCOOH} \mathrm{or} \mathrm{H}_{2} \mathrm{SO}_{4}$, etc.) to react with alkaline reserve compounds such as $\mathrm{Mg}(\mathrm{OH})_{2}$ and $\mathrm{MgCO}_{3}$ (Hubbe et al. 2017). Any $\mathrm{Mg}\left(\mathrm{HCO}_{3}\right)_{2}$ present in the paper also could take part in such reactions. Another option, based on the patent of Zitzmann et al. (2002), is to expose the deacidified books to a mist of aqueous solution. Potential benefits of such treatment include completion of any incomplete reactions between acidic species in the paper and the nearby alkaline agents deposited during the treatment (Hubbe et al. 2017). In addition, various conservation treatments, such as strengthening agents, may be applied to the paper in such a step 
(Zitzmann et al. 2002; Katuscak et al. 2007; Brückle and Banik 2011a). Issues related to remoistening paper after deacidification were considered in more detail earlier (Hubbe et al. 2017).

\section{Post-reactions}

Some investigators have proposed that certain reactions take place after the completion of the deacidification cycle, as described in the preceding steps. In the case of the Battelle system, Wittekind (1994a) proposed that after evaporation of the solvent, the alkoxides react with moisture from the air or from the paper to produce the corresponding hydroxides of magnesium and titanium. It was further proposed that the $\operatorname{Ti}(\mathrm{OH})_{2}$ formed in the course of treatment or during equilibration is gradually converted to $\mathrm{TiO}_{2}$ during storage of the books. However, Blüher and Vogelsanger (2001) indicated a lack of firm evidence of whether the alkaline reserve species left in the paper after treatment was in the form of hydroxides, carbonates, bicarbonates, or mixed carbonates. Hon (1989) proposed that the alkaline reserve materials deposited in the paper can react with acids such as sulfuric acid according to reactions such as the following:

$$
\begin{aligned}
& \mathrm{Mg}(\mathrm{OH})_{2}+\mathrm{H}_{2} \mathrm{SO}_{4} \rightarrow \mathrm{MgSO}_{4}+\mathrm{H}_{2} \mathrm{O} \\
& \mathrm{MgCO}_{3}+\mathrm{H}_{2} \mathrm{SO}_{4} \rightarrow \mathrm{MgSO}_{4}+\mathrm{H}_{2} \mathrm{CO}_{3}
\end{aligned}
$$

Whether or not such reactions can occur efficiently in the absence of an aqueous phase does not seem to have been reported within the literature related to deacidification. Also, if the sulfuric acid is able to react directly with an alkoxide-type reagent during the immersion step, then it presumably would not be present later to undergo the reaction indicated by Eqs. 5 and 6.

So-called "re-acidification", i.e. the observation that in the long run papers that have been deacidified tend to show a decrease of surface $\mathrm{pH}$ (Ahn et al. 2011), points towards either (a) insufficient alkaline reserve to be deposited in the first place or b) inefficient reaction between acid species and alkaline reserve material present at different positions within the microstructure of the paper. Explanation " $b$ " is consistent with the observation by Shahani and Harrison (2002) that carboxylic acids can continue to accumulate during storage of alkaline papers containing large amounts of calcium carbonate filler, which can be regarded as an alkaline reserve material. The inefficiency of reactions between acidic species within paper and alkaline reserve materials taking place under dry conditions are supported by the general findings discussed in an earlier review article (Hubbe et al. 2017). It is recommended that future studies be carried out to quantify and better understand such reacidification phenomena.

\section{Evidence of Effectiveness}

Before considering further the mechanism of solvent-based deacidification, it is important to weigh evidence of the effectiveness of such treatments. Criteria to be considered here, in the light of published reports, include efficacy factors (based on accelerated aging treatments, followed by tests of folding endurance), evaluation of cellulose degree of polymerization (DP), $\mathrm{pH}$, alkaline reserve levels, and evidence of the neutralization of carboxylic acids present in the paper. 


\section{Efficacy factors}

An efficacy factor expresses by how many times the rate of strength loss or DP loss, during accelerated aging, is decreased by a deacidification treatment in comparison to untreated acidic paper from the same source exposed to the same accelerated aging conditions. To give a simple example, suppose a certain untreated acidic paper loses half of its folding endurance during a standard accelerated aging test. Suppose now that a deacidified sample of the same paper loses only one quarter of its strength due to the same aging treatment. In such a case the efficacy factor would be 2. Andres et al. (2008) carried out such an analysis, considering not only solution-based nonaqueous treatments, but also suspension-based treatments, as well as the most established method (for single sheets of paper) consisting of aqueous treatments. While the aqueous treatments achieved the highest efficacy factors (values reaching 8), the solution-based nonaqueous treatments achieved a strong second-place standing, with efficacy factors of 4 or higher. Similarly, positive efficacy results for the solution-based nonaqueous systems were reported by others (Brandis 1994; Blüher and Vogelsanger 2001; Banik 2005; Ramin et al. 2009; Katuscak et al. 2012; Potthast and Ahn 2017). The review article by Hubbe et al. (2017) presents such information in tabulated form, showing clearly that the alkoxide-based deacidification technologies generally have greatly outperformed technologies based on suspensions of alkaline particles in nonaqueous media.

\section{Alkaline reserve}

Because it is well known that acidity can continue to accumulate in stored paper items, due either to the degradation processes or the arrival of acidic components such as $\mathrm{SO}_{2}$ and nitrogen oxides in polluted air (Smith 1969; Blüher and Vogelsanger 2001, Menart et al. 2014), it makes sense that deacidified paper should contain a reserve of compounds capable of neutralizing such freshly-arriving acid species. The alkaline reserve level is determined by titrating a specified amount of paper material with strong acid, after it has been deacidified (ISO 1994). As reported, solution-based nonaqueous deacidification treatments have demonstrated effectiveness in providing alkaline reserve (Brandis 1994; Bukovský 2005). Issues related to whether or not such acidic species are able to react efficiently with alkaline reserve substances during typical conditions of storage of books remains a matter of concern (Hubbe et al. 2017). In cases where it may be important to achieve a target level of alkaline reserve, in addition to effective neutralization of acidic species in the paper, a strategy employed by Jablonsky et al. 2013) can be considered. These researchers used a combined treatment with $\mathrm{MgO}$ particles and methyl methoxy magnesium carbonate added to an inert liquid.

Uniformity of distribution of the alkaline reserve material is an area of interest. For instance, when evaluating a system based on ethoxymagnesium ethylcarbonate (EMEC), Clark et al. (1998) reported uneven distribution following spray treatment of papers that were either of heavy weight or high in moisture content. Notably, such paper had not been dried before the treatment, as it would have been in one of the established mass deacidification processes. Lienardy (1994) reported a relatively wide distribution of alkaline reserve in different parts of books treated by the Wei T'o process. Presumably, such issues were addressed more recently by process changes, such as mild external heating and lower applied vacuum during the evaporation stage of treatment (Smith 1977). MacInnes and Barron (1992) found evidence of non-uniform distribution of alkaline 
reserve in paper treated with magnesium butoxytriglycolate. According to Ramin et al. (2009), all of the solution-based systems that they evaluated gave even distributions of alkaline reserve. However, as discussed in the DIN recommendation of Hofmann and Wiesner (2015), there is a need for standardization and improvements of methods to determine the uniformity of distributions of alkaline reserve particles.

$p H$

Though there is widespread agreement that an adequate and uniformly distributed alkaline reserve is an important goal in the deacidification of books, it is also important to judge whether or not the fibers, interior regions, or nano-scale spaces within the book have been converted to a neutral or alkaline condition. Brandis (1994) reported that paper treated by the Wei T'o process had an alkaline $\mathrm{pH}$. Though $\mathrm{pH}$ is relatively easy to measure and the results help to substantiate the fact that there is alkaline reserve present in treated paper, they tend to be inconclusive regarding whether neutralization reactions have been completed at a nano-scale level (Hubbe et al. 2017). As noted by Clark et al. (1998), one is really just measuring the water used to locally moisten the paper, and that water might act as the essential factor in enabling interaction between acidic and alkaline species that happen to be both present in the deacidified paper. So the detection of alkaline $\mathrm{pH}$ within a droplet of water placed on the surface of paper does not guarantee that all locations within the paper's microstructure had been free of acidity (Ahn et al. 2011).

Wittekind (1994a) used a kind of litmus test to carry out a critical demonstration in the case of solution-based deacidification. The paper was sprayed with a solution of $0.1 \%$ chlorophenol, which changes from yellow to violet with increasing $\mathrm{pH}$. By this means the Battelle scientists were able to verify the uniform alkaline $\mathrm{pH}$ of their preferred treatment system, in contrast to some other samples treated in different ways.

\section{Neutralization of carboxylic acids}

Only in exceptional cases have published studies provided direct evidence of the neutralization of acidic species in paper as a result of deacidification measures. Banik (2005) reported the results of measuring acetic acid content in matched sets of paper documents subjected to different deacidification processes. Acetic acid was still detected within specimens that had been treated by two processes employing suspensions of alkaline particles in nonaqueous carrier. The Battelle process (Papersave), which employs dissolved reagents, resulted in there being no remaining acetic acid in the paper. Headspace analysis, in which one quantifies the composition of molecules in the gas phase adjacent to stored books, offers promise to detect this kind of evidence (Banik 2005; Hrivnak et al. 2009a,b; Area and Cheradame 2011; Becker et al. 2016). Capillary electrophoresis (CE) analysis resulted in rather more acid formation in paper with 5\% calcium carbonate filler compared to the control sample, which could indicate that alkaline reserve plays a role in trapping acids before neutralization (Shahani and Harrison 2002).

\section{Adverse effects}

Perhaps even more important than assuring effectiveness of a proposed deacidification treatment, curators and conservators of important archival and library collections insist that no harm be done to the treated items. The importance given to the 
individual potential adverse effects might differ among institutions. Some such effects are noted below.

Color and brightness: Andres et al. (2008) reported that treatment of books using a high concentration of double alkoxide (magnesium and titanium ethoxides) yielded darkening or yellowing. Hey (1981) and Blüher and Vogelsanger (2001) had earlier noted measurable changes in color of all treated samples, for the same kind of treatment. Blüher and Vogelsanger (2001) judged such changes to be insignificant in comparison to the expected changes due to natural aging.

Feel and grit: Andres et al. (2008) also noted a change in the feel of paper that had been treated by a solution-based nonaqueous procedure. Kelly and Fowler (1978) noted that some of the treated paper had a gritty feel after various treatments using MMMC dissolved in either methanol or a methanol-chlorofluorocarbon mixture. Hon (1989) noted a tendency for a gritty feel if excessive moisture was present during deacidification with magnesium methoxide. Smith (2013), as part of justifying a combined MMMC-double alkoxide system, noted a tendency for the double alkoxide system by itself to result in gritty deposits when used at high levels. In summary, it appears that all of these issues can be minimized, as long as there is sufficient attention paid to quality control (Blüher and Vogelsanger 2001; Banik et al. 2006; Andres et al. 2008).

Excessive alkalinity: Too high a $\mathrm{pH}$ level of treated paper has been found to act as a catalyst for oxidative decomposition of paper (Kolar et al. 1998). Ahn et al. (2012c) concluded that because such oxidation tends to take place at the ends of cellulose polymer chains, the overall effect on paper properties tends to be minor. Treatments involving magnesium compounds sometimes have been regarded favorably, since the buffering systems are not highly alkaline (Green and Leese 1991). Smith (1977) added that $\mathrm{Mg}(\mathrm{OH})$ can be expected to sequester the ions of metals such as iron, copper, and cobalt, which would be expected to catalyze such oxidation, if not bound. On the other hand, the chemistry of magnesium in paper tends to be less well defined than that of calcium, which leads some conservators to prefer deacidification treatments involving calcium (Banik and Brückle 2011). Smith (1979) found strong evidence in support of the oxidation mechanism, showing cases in which accelerated aging in the presence of nitrogen gas, rather than air (which has $20 \%$ oxygen), resulted in only about half the rate of decrease in folding endurance. The complexity of the issue is highlighted by the findings of Strlič et al. (2003), who found that while the catalytic effect of iron ions for the oxidation reaction was suppressed at increased $\mathrm{pH}$, the catalytic effect of copper ions was not.

\section{Solvent rings, dye solubilization, and color bleed}

Solvent rings, sometimes also referred to as "newton rings," in the pages of treated books can be regarded as evidence of a deposit of a thin film of deacidification reagent that had not been able to penetrate the paper nor was it removed properly. They are thought to be controllable (Banik 2005), while dye solubilization and color bleed are inherent to solvent based processes that generate alcohols in the course of deacidification (Banik 2005). Lienardy (1994) observed such features when inspecting some books treated by the 
Wei T'o process. Ramin et al. (2009) observed some instances of color bleed when inspecting some volumes that had been deacidified by the Battelle process.

\section{MECHANISM OF NONAQUEOUS SOLUTION DEACIDFICATION}

In light of the evidence discussed in the preceding section, mechanistic aspects of the deacidification process will be considered next. This section will consider various mechanistic explanations for the effectiveness of alkoxide-based deacidification systems. In theory it makes sense that a dissolved alkaline species ought to be able to undergo neutralization reactions with certain acid species in the paper, and this section will consider the extent of evidence to support such a hypothesis. Reactions with acidic species will be considered first, and then reactions involving water molecules.

\section{Organic-phase Reactions}

Evidence of reaction of the organometallic agent with organic acids

It is well known that the acid-catalyzed decomposition of paper can result in increased levels of carboxylic acids (Shahani and Harrison 2002; Banik 2005), which may be expected to catalyze further hydrolysis of the cellulose in the paper (Zervos and Moropoulou 2005; Calvini et al. 2007). So it is important to consider whether such species will react with magnesium methoxide and related agents. Regarding whether or not alkoxide-based agents are capable of reacting directly with carboxylic acid species within paper, the literature related to mass deacidification provides some strong circumstantial evidence. As has been noted in a previous article (Hubbe et al. 2017), nonaqueous deacidification methods employing solubilized alkoxide species were able to effectively decrease rates of loss of paper strength during accelerated aging, whereas systems relying on dispersions of alkaline particles have been found to be either less effective or ineffective. One way to explain such findings is that the dissolved alkaline species are able to react directly with and neutralize carboxylic acid species within the paper. Such a reaction might reasonably occur already during the initial immersion step, or possibly during subsequent equilibration of deacidified books in ambient air. Because alkoxide and related chemicals are known to react rapidly with moisture (Carnes and Klabunde 2000; Diao et al. 2002), the opportunity for their reaction directly with acidic species in paper may need to have happened before all of their reactivity has been consumed in such reactions with water.

\section{Evidence from the chemistry literature}

The chemical literature provides many examples in which metal alkoxides react with carboxylic acids (Kickelbick et al. 2002; Turbova et al. 2002). Such studies have relevance when considering (a) the reaction of ordinary alkoxides (as in the original Wei T'o recipe and in the modern Batelle Papersave process) or (b) the reaction of carbonated forms of alkoxides in other treatment systems. Table 4 summarizes such studies, showing the reactive alkoxide and carboxylic species. Essentially all of the listed work was carried out in organic solvents at room temperature, and the reactions generally were reported to be relatively rapid and complete. 
Table 4. Reported Reactions between Metal Alkoxides and Carboxylic Acids

\begin{tabular}{|l|l|l|l|}
\hline Alkoxide species & Carboxylic acid & Details & Citation \\
\hline Al alkoxides & Carboxylic acids & Review article & $\begin{array}{l}\text { Lichtenberger \& } \\
\text { Shubert 2010 }\end{array}$ \\
\hline $\mathrm{Ce}($ III) alkoxides & Sterically modified & Pyridine solutions & Boyle et al. 2006 \\
\hline Ge alkoxides & Salicilic, mandelic & Yields 40-90\% & $\begin{array}{l}\text { Mathur \& Mehrotra } \\
1967\end{array}$ \\
\hline Ti isopropoxide & Formic & Prompt precipitation & Boyle et al. 1998 \\
\hline Ti n-butoxide & Unsaturated diacids & $1: 1$ reactions shown & Buyuktas 2006 \\
\hline Ti butoxides & Chloroacetic acids & Room temperature & Ambreen et al. 2013 \\
\hline Ti alkoxides & Sterically hindered & - & Boyle et al. 1999 \\
\hline $\mathrm{Ti}$ alkoxides & Endogenous organic & Sol-gel coatings & Urlaub et al. 2000 \\
\hline Yttrium alkoxides & Acetic, methacrylic & Dry solvents & Fric et al. 2006 \\
\hline $\begin{array}{l}\mathrm{Zr}\left(\mathrm{OC}_{4} \mathrm{O}_{10}\right)_{4}, \\
\mathrm{Zr}\left(\mathrm{OC}_{3} \mathrm{O}_{8}\right)_{4},\end{array}$ & Methacrylic & $\begin{array}{l}\text { Slow formation of } \\
\text { clusters }\end{array}$ & Kickelbick et al. 2002 \\
\hline $\mathrm{Zr}$ alkoxides & $\begin{array}{l}\text { Formic, acetic, iso- } \\
\text { butyric, trimethyl- } \\
\text { acetic, t-butylacetic }\end{array}$ & Formed quickly & Boyle et al. 2005 \\
& & & \\
\hline
\end{tabular}

A consistent theme of the sources cited in Table 4 is that one of the initial reactions of divalent metal alkoxides with carboxylic acid species can be represented by an equation such as (Mathur and Mehrotra 1967),

$$
\mathrm{M}(\mathrm{OR})_{2}+\mathrm{R}^{\prime} \mathrm{COOH} \rightarrow \mathrm{ROM}-\mathrm{OOCR}{ }^{\prime}+\mathrm{ROH}
$$

where " $\mathrm{M}$ " in this example represents a divalent metal such as $\mathrm{Mg}$ or $\mathrm{Zn}$. Because the compound ROM-OOCR' still contains an alkoxide group, a reaction as follows can be expected when it is exposed to a water molecule:

$$
\text { ROM-OOCR' }+\mathrm{H}_{2} \mathrm{O} \rightarrow \text { HOM-OOCR' }+\mathrm{ROH}
$$

Nothing was found in the literature regarding the reactive nature of compounds such as HOM-OOCR'. However, the formula suggests that in aqueous solution this compound would be solubilized as the ions $\mathrm{M}(\mathrm{OH})^{+}$and $\mathrm{R}^{\prime} \mathrm{COO}^{-}$. This is essentially the composition of the conjugate base of a carboxylic acid, suggesting that Eq. 8 completes the neutralization process.

In the case of carbonated magnesium propoxylate, Henniges et al. (2012) found evidence to support the reaction,

$$
\begin{aligned}
& {\left[\left(\mathrm{CH}_{3} \mathrm{CH}_{2} \mathrm{CH}_{2} \mathrm{OCOO}\right)_{2} \mathrm{Mg}\right]+2 \mathrm{RCOOH} \rightarrow} \\
& \qquad \mathrm{Mg}(\mathrm{OOCR})_{2}+2 \mathrm{CH}_{3} \mathrm{CH}_{2} \mathrm{CH}_{2} \mathrm{OH}+2 \mathrm{CO}_{2}
\end{aligned}
$$

and they also proposed a similar reaction with any sulfuric acid present in the paper,

$$
\begin{aligned}
{\left[\left(\mathrm{CH}_{3} \mathrm{CH}_{2} \mathrm{CH}_{2} \mathrm{OCOO}\right)_{2} \mathrm{Mg}\right]+\mathrm{H}_{2} \mathrm{SO}_{4} \rightarrow } \\
\mathrm{MgSO}_{4}+2 \mathrm{CH}_{3} \mathrm{CH}_{2} \mathrm{CH}_{2} \mathrm{OH}+2 \mathrm{CO}_{2}
\end{aligned}
$$

As mentioned earlier, the reaction described in Eq. 10 might require sufficient water to be present so that $\mathrm{H}_{2} \mathrm{SO}_{4}$ would be present in ionized form. 
In addition to the reaction combinations listed in Table 4, it is worth noting that the already-discussed reaction of carbon dioxide with magnesium methoxide (Finkbeiner and Stiles 1963; Kelly et al. 1977) can be regarded as a reaction with carbonic acid, a carboxylic acid species. Thus, the formation of MMMC can be regarded as yet another example of a metal methoxide reacting with a carboxylic acid.

It is a fair question, once such a reaction with $\mathrm{CO}_{2}$ has taken place, as to whether the formed MMMC or CMP will further react with various carboxylic acid species in the available time during immersion or later as the sheet is equilibrated with a humid atmosphere. Because the question of MMMC's ability to react with carboxylic acids is so central to certain mass deacidification technologies, it is hoped that this will become the topic of some future research.

\section{Reactions Involving Moisture}

In addition to possible reactions with acid species within paper, it is also important to consider the manner in which metal alkoxides and related chemicals interact with water, including any water in the nonaqueous solvent, in the paper to be treated, or in the air that is present during the processing or later equilibration of the books.

Several studies of solution-based nonionic deacidification processes have reported the deposition of particles that are either visible or detectable by their gritty feel (Smith 1979; Hon 1989; Wittekind 1994b; Clark et al. 1998). The easiest way to account for such particles is to assume an initial reaction between an alkoxide entity and water, especially if such a reaction is allowed to take place with trace water in the bulk of the nonaqueous solution. For instance, the reaction between a divalent metal alkoxide (when assuming that the metal is $\mathrm{Mg}$ ) and water can be written as (Carnes and Klabunde 2000; Diao et al. 2002):

$$
\mathrm{Mg}(\mathrm{OR})_{2}+2 \mathrm{H}_{2} \mathrm{O} \rightarrow \mathrm{Mg}(\mathrm{OH})_{2}+2 \mathrm{ROH}
$$

The metal hydroxide $\left.(\mathrm{MgOH})_{2}\right)$, having neutral charge, would be expected to be insoluble and to precipitate from solution. Alternatively, MMMC can be expected to follow an analogous reaction (given earlier as Eq. 4),

$$
\mathrm{CH}_{3} \mathrm{OMgOCO}_{2} \mathrm{CH}_{3}+\mathrm{H}_{2} \mathrm{O} \rightarrow \mathrm{MgCO}_{3}+2 \mathrm{CH}_{3} \mathrm{OH}
$$

In the case of CMP, the corresponding reaction could be written as,

$$
\mathrm{Mg}\left(\mathrm{OCO}_{2} \mathrm{CH}_{3}\right)_{2}+\mathrm{H}_{2} \mathrm{O} \rightarrow \mathrm{MgCO}_{3}+\mathrm{CO}_{2}+2 \mathrm{CH}_{3} \mathrm{OH}
$$

Research findings suggest that Eq. 11 may be merely the first step in either a polymerization or a particle-forming process, depending on the details of chemistry and treatment conditions. For example, Stengl et al. (2003) found that $\mathrm{MgO}$ nanoparticles could be formed when the reaction was carried out in the presence of ultrasonic vibrations in a toluene solution, to which distilled water was added. Ranjit and Klabunde (2005) observed the formation of gel-like precipitates when magnesium methoxide dissolved in toluene, benzene, anisole, or several more polar solvents were exposed to water. The nonpolar solvents were reported to promote the gelation process. Gel structures imply a kind of polymerization leading to slender fibrils, which may become tangled or otherwise immobilized, such that a lot of water can be loosely held within a nano-scale skeletal framework. Diao et al. (2002) concluded that gels formed by hydrolysis of magnesium 
methoxide were polymeric based on factal analysis. They also proposed that the reaction of alkoxide with $\mathrm{Mg}-\mathrm{OH}$ groups gives rise to $\mathrm{Mg}-\mathrm{O}-\mathrm{Mg}$ links, which can serve as the basis for polymerization.

\section{Reaction with water molecules bound at the paper surface}

It was proposed by Smith (1970) that magnesium methoxide may react with residual water in the treated paper, thereby becoming insolubilized. Hubbe et al. (2017) suggested that the reaction between magnesium alkoxide-based species and water at the paper surface could be a favorable way to deposit alkaline reserve materials directly onto the fibers. The idea is that most such deposited material, especially when deposited in nano-scale spaces, would tend to be sufficiently incorporated in the paper, such that it would be unlikely to show up as solids in the excess solution returned to storage after treatment (Smith 1977; Eggersdorfer et al. 1990).

It has been proposed that there should be an optimum water content in paper to be treated with a solution-based nonaqueous deacidification agent (Hubbe et al. 2017). Too much moisture in the paper, and the alkoxide-based agent would tend to be consumed by its reactions with water, with the possible deposition of external grit, before reaction with the internal structures of the paper. Such effects would likely be different for different alkoxide-based chemicals due to their differing rates of reaction with water. An optimized amount of moisture might serve to bring about prompt precipitation of a relatively uniform layer of insolubilized alkaline reserve material. Too little moisture might potentially give rise to an uneven distribution of the agent, since the still-active and soluble alkoxide-based species later would tend to flow with the nonaqueous solvent in the direction where evaporation is taking place (Smith 1977; Kelly and Fowler 1978). It is worth noting that, because of the ratio of molecular mass of water to $\mathrm{MgCO}_{3}(18: 84.3)$, a $0.5 \%$ level of water in paper, as suggested for the Wei T'o process (Hon 1989; Brandis 1994), would be predicted to provide a means of immediately depositing about $2.3 \%$ of $\mathrm{MgCO}_{3}$, assuming that $100 \%$ of such water is capable of reacting with the MMMC used in that process. It might be argued that a moisture content of below 1\%, as specified in the Battelle process (Wittekind 1994a; Clark et al. 1998; Blüher and Vogelsanger 2001), might achieve almost the same optimum level, noting that the double alkoxide used in that process, in addition to depositing the alkaline reserved material (related to $\mathrm{Mg}$ compounds), also is expected to deposit $\mathrm{Ti}$ in the form of its hydroxide or oxide.

\section{Can the agent become depleted before it reaches the paper surface?}

It is well known that when solutions are examined by paper chromatography, many of the components have a slower average rate of progress through the paper material in comparison to the solvent (Zweig and Whittaker 1967). When a solute has a significant affinity for the stationary (paper) phase in comparison to its affinity for the solvent, the process of equilibration with the surface will tend to make the solute molecules lag behind the solvent molecules, on average, during the initial permeation of the paper. In considering the situation depicted in Fig. 1, one can simplify the discussion by assuming that the pages of the book are much more permeable to the fluid in comparison to the book's cover. Thus, the situation might be illustrated as in Fig. 2. As shown, the degree to which the treatment solution becomes depleted during the initial infusion step might be insignificant or it could have a dominant effect, depending on the relative affinity of 
alkoxide-related compounds for the cellulosic surfaces. Another mechanism that can be expected to contribute to the effect shown in Fig. 2 would be a relatively rapid reaction between an alkoxide-based compound and either water or acidic compounds in the stationary (paper) phase in comparison to the rate of infusion. The general effects shown in Fig. 2 are consistent with descriptions given by Kelly and Fowler (1978), who attributed such observations to relatively poor solubility of the deacidification agent in various solvents.

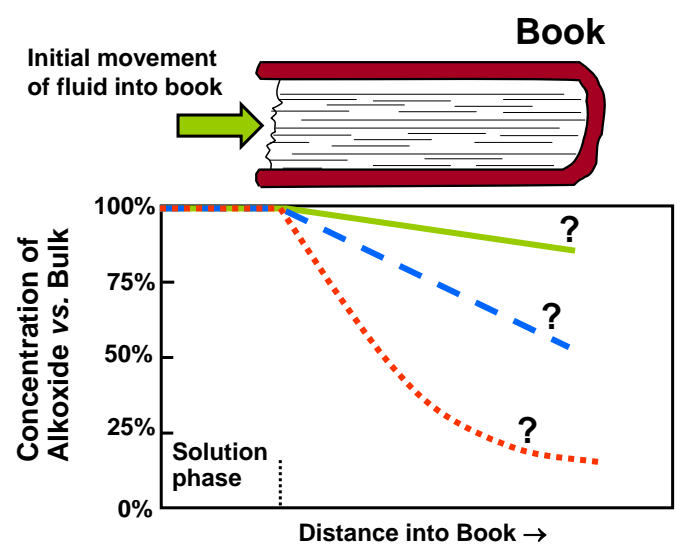

Fig. 2. Hypothetical depletion of an alkoxide compound during an assumed one-directional diffusion of nonaqueous solution into a book. Three hypothetical curves are shown, representing different initial concentrations of the alkoxide-related compound.

\section{Issues Related to Post-Moistening}

Issues related to completion of deacidification

Issues related to completion of deacidification reactions were dealt with in an earlier review article (Hubbe et al. 2017). The idea is to neutralize any remaining acidic species within the microstructure of nominally deacidified books. The cited article was particularly focused on an especially challenging situation - books that had been deacidified by simple distribution of micron-sized alkaline mineral particles in the absence of moisture. It has generally been assumed that the commercial alkoxide-based massdeacidification systems are more effective in neutralizing acidic groups within the treated books in comparison to such "dry particle" treatments. As noted in Table 5, there are both logical and evidence-based reasons to support such an expectation.

Table 5. Reasons to Expect Greater Completion of Deacidification when a Reactive Alkaline Agent Dissolved in a Carrier Fluid is Employed

\begin{tabular}{|c|l|}
\hline Theoretical reasons & Selected citations \\
\hline $\begin{array}{c}\text { Better distribution of alkaline agent, possibly at } \\
\text { a molecular scale }\end{array}$ & $\begin{array}{l}\text { Ramin et al. 2009; Ahn et al. } \\
2012 \mathrm{~b}\end{array}$ \\
\hline Access to a wide range of pore sizes & Potthast and Ahn 2017 \\
\hline Ability of the agent to react with acidic species & As summarized in this article \\
\hline Evidence-based reasons & \\
\hline High performance in accelerated aging tests & Andres et al. 2008; Ahn et al. 2013 \\
\hline The color of pH-sensitive dye in the deacidified paper & Wittekind 1994a \\
\hline Less evolution of gases from the deacidified paper & Banik 2005 \\
\hline
\end{tabular}


Even in cases where most of the original acidity within a book may have been effectively neutralized during a nonaqueous solution-based deacidification treatment, it is still reasonable for conservators to consider moistening procedures among the possible options for future treatments. As discussed earlier in this article, new acidity can be expected to gradually form within the paper as a result of aging reactions (Calvini et al. 2007; Zervos 2007). For example, the acid-catalyzed hydrolysis of acetate groups within the stored paper can lead to the generation of acetic acid (Polovka et al. 2006; Zervos 2007; Jablonsky et al. 2012). Acidic pollutant gases such as $\mathrm{SO}_{2}$ can further contribute to the problem (Smith 1969). Vapors of acetic or formic acids might reasonably migrate from an adjacent book or book cover during library storage. In the past it was widely believed that such acidity would be neutralized passively due to the presence of alkaline reserve materials present in a deacidified book, but a recent review of the literature suggests that moistening may be required to bring about reactions between acidic species and solid alkaline particles within paper (Hubbe et al. 2017).

\section{FUTURE OUTLOOK AND RECOMMENDATIONS}

In light of the published information considered in this review, perhaps the most important point to emphasize is the continuing urgent need for prompt deacidification of millions of at-risk books in libraries throughout the world. That topic is considered below. Next, to summarize the findings of this literature review, a somewhat more complete account is beginning to emerge regarding how the nonaqueous solution-based mass deacidification methods work. Finally, some recommendations will be given concerning needed further research in such topics as mechanistic aspects of deacidification, prospects for achieving other paper-conservation goals, and some suggestions for developmental efforts to further improve the performance of future nonaqueous solution-based mass deacidification systems.

\section{Priority for Early and Widespread Treatment of Irreplaceable Items}

As was stated by Blüher and Vogelsanger (2001), "Despite all these promising research projects, it must be noted that the deterioration of paper is advancing rapidly, and waiting for the perfect system presents a much greater risk to our written heritage than using a less perfect method." However, in light of recent findings, it is important to employ a deacidification system having well-demonstrated effectiveness that has been established by independent studies. The hazards of acidic paper have been very well documented (Smith 1969; Williams 1971; Wilson and Parks 1979; Smith 1987). The self-catalytic nature of such destruction, leading to acceleration and catastrophic failure of books, was discussed in an earlier review article (Hubbe et al. 2017). Deacidification has the ability to substantially increase the useful lifespan of books, the paper of which was formed in the presence of rosin and aluminum sulfate under acidic conditions, and which can be expected to become more acidic due to chemical processes, as well as air pollution, which affect books during storage. 


\section{An Emerging View of How the Nonaqueous Solution Systems Work}

Based on the work reviewed and discussed in this article, it is possible now to assemble the following general description of the mode of action of nonaqueous solutionbased mass deacidification systems (see also Fig. 3):

1. The dissolved state of the alkaline compound (such as an alkoxide or carbonated form of alkoxide) allows it to diffuse to the paper surface, ideally such that pores within the paper microstructure and also the cell wall of the fiber encounter the active agent. Insufficient solubility might explain non-ideal performance, such that the alkaline compound lags behind the solvent while in the process of diffusing through the pore structure of a book during immersion (Kelly and Fowler 1978).

2. Depending on the moisture content of the paper or in the fluid used as a solvent, the alkaline compound also may react with water before reaching the paper surface, yielding alkaline reserve compounds (such as $\mathrm{Mg}(\mathrm{OH})_{2}, \mathrm{MgCO}_{3}$, or $\mathrm{MgO}$, or mixtures thereof), which may be retained unevenly on or in the paper, if not drained away with the excess nonaqueous medium after the immersion step in the process.

3. A portion of the alkaline compound can be expected to react with water molecules adsorbed on the paper surfaces or molecularly associated with the paper solids as water of hydration. Alkaline reserve compounds formed in such interactions are assumed to remain bound within the paper microstructure. Such reactions, if optimized, offer a mechanism by which to achieve relatively uniform distribution of alkaline reserve agent associated with the paper microstructure.

4. If sufficient alkaline compound was present in the initial nonaqueous mixture, then, in the case of magnesium methoxide, ethoxide, and similar agents, one can expect near-quantitative neutralization of protonated forms of carboxylic acids in the paper microstructure. Presumably, the same result can be expected in the case of methoxymagnesium methylcarbonate (MMMC) or similar agents such as carbonated magnesium propoxylate (CMP).

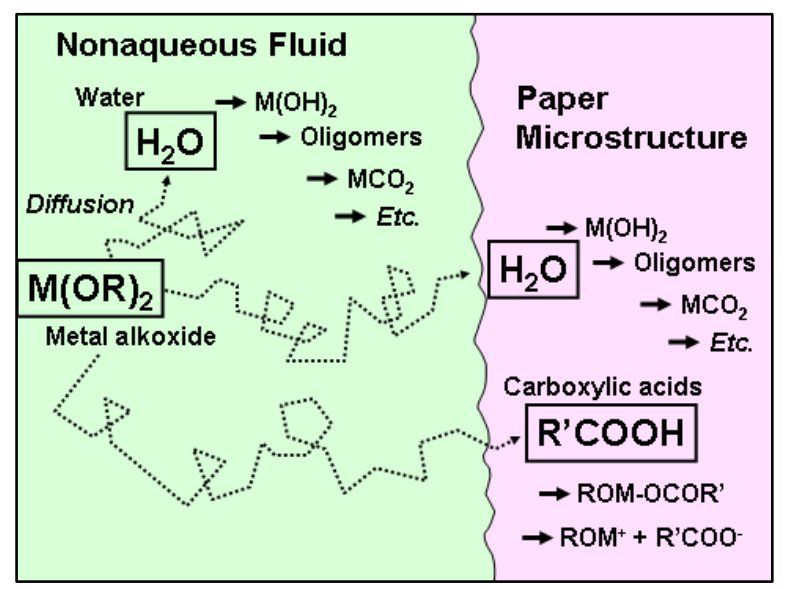

Fig. 3. Proposed competition among possible reaction paths or locations depending on the diffusion of alkoxide molecules from a nonaqueous solution toward either water molecules (contaminating the nonaqueous fluid or in the paper) and carboxylic acids in the paper 
If one accepts the premise, as outlined above, that some of the most effective mass deacidification processes entail direct, immediate reaction with acidic species in the paper, as well as direct reaction with residual water in the paper to lay down a relatively uniform content of alkaline reserve, then it may be possible to rationalize why some other treatment options have been found to be generally much less effective (Hubbe et al. 2017). Some other reported work supports effectiveness of using suspensions of alkaline particles such as $\mathrm{MgO}$ (Polovka 2006; Jezewska et al. 2013). Possibly such deacidification based on nonaqueous suspensions of alkaline particles, rather than solutions, can be more effective when using nano-scale particles (Wojciak 2016; Bastone et al. 2017; Poggi et al. 2017; Sistach et al. 2017; Saoud et al. 2018). However, as already has been reported (Hubbe et al. 2017), the hypothesis that effective, reliable deacidification can be achieved in the absence of soluble, reactive species has not been well supported by published research (Potthast and Ahn 2017).

Carbonation of alkoxide compounds, since it tends to make the material less reactive, can be expected to affect the scenario depicted in Fig. 3. In the case of MMMC, it is important to keep in mind that the reagent has two kinds of functionality - a bound methylcarbonate group and an alkoxide group. The latter can presumably react according to Eq. 14, which is essentially the same as the more general equation, Eq. 7:

$$
\mathrm{CH}_{3} \mathrm{OMgOCO} \mathrm{CH}_{3}+\mathrm{R}^{\prime} \mathrm{COOH} \rightarrow \mathrm{R}^{\prime} \mathrm{COO}-\mathrm{MgOCO}_{2} \mathrm{CH}_{3}+\mathrm{CH}_{3} \mathrm{OH}
$$

Future studies would be needed in order to determine whether or not the reaction shown as Eq. 14 plays a significant role or if some other reaction path is followed. One of the stated advantages of the carbonated form, MMMC, is a slower reaction with water (Kelly et al. 1977). Figure 4 shows changes, relative to the previous figure, in order to emphasize the consequences of this lower reactivity, plus the ability of MMMC to directly form the carbonate species on the occasion of its eventual interaction with water.

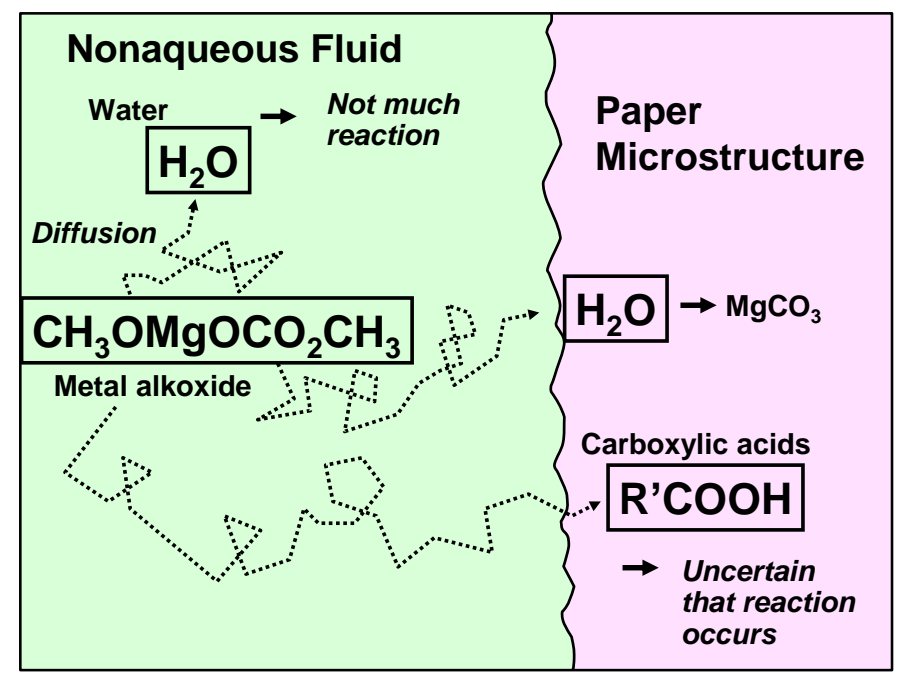

Fig. 4. Proposed competition among possible reaction paths or locations depending on the diffusion of methoxymagnesium methylcarbonate (MMMC) molecules from a nonaqueous solution toward either water molecules (contaminating the nonaqueous fluid or in the paper) and carboxylic acids in the paper 
As noted by Kelly et al. (1977), MMMC is able to form $\mathrm{MgCO}_{3}$ directly upon exposure to the remnants of moisture present in paper. This is potentially a great advantage, since such a reaction immediately results in an alkaline reserve compound deposited within the small pores of the paper, not even having to wait until later equilibration of the paper with the environment (Kelly et al. 1977). On the other hand, future research may be needed to determine whether or not MMMC would need to be supplemented with magnesium methoxide or other alkoxide species to ensure full neutralization of carboxylic acids present in the paper to be treated.

It is noteworthy that the very effective "double alkoxide" system (Batelle) does not employ carbonated alkoxide species. Rather, only simple alkoxides $\left(\mathrm{MgOCH}_{2} \mathrm{CH}_{3}\right.$ and $\mathrm{TiOCH}_{2} \mathrm{CH}_{3}$ ) are used. The recent patented system by Smith (2013), which combines the double alkoxide with MMMC merits further examination to determine whether it offers an ideal combination of reactivity with carboxylic acid species, coupled with an ability to directly form alkaline reserve materials within the paper microstructure during the immersion step.

In the case of carbonated magnesium propoxylate (CMP), Henniges et al. (2012) proposed the following reactions,

$$
\begin{aligned}
{\left[\left(\mathrm{CH}_{3} \mathrm{CH}_{2} \mathrm{CH}_{2} \mathrm{OCOO}\right)_{2} \mathrm{Mg}\right] } & +2 \mathrm{H}_{2} \mathrm{O} \rightarrow \\
\mathrm{MgO} & +2 \mathrm{CH}_{3} \mathrm{CH}_{2} \mathrm{CH}_{2} \mathrm{OH}+2 \mathrm{CO}_{2}
\end{aligned}
$$

and

$$
\begin{aligned}
& {\left[\left(\mathrm{CH}_{3} \mathrm{CH}_{2} \mathrm{CH}_{2} \mathrm{OCOO}\right)_{2} \mathrm{Mg}\right]+4 \mathrm{H}_{2} \mathrm{O} \rightarrow} \\
& \qquad \mathrm{Mg}(\mathrm{OH})_{2}+2 \mathrm{CH}_{3} \mathrm{CH}_{2} \mathrm{CH}_{2} \mathrm{OH}+2 \mathrm{CO}_{2}
\end{aligned}
$$

The resulting $\mathrm{MgO}$ and $\mathrm{Mg}(\mathrm{OH})_{2}$ species presumably can then interact with atmospheric $\mathrm{CO}_{2}$ to form $\mathrm{MgCO}_{3}$ as a likely stable alkaline reserve compound in the paper (Henniges et al. 2012). Another question that can be considered in future research is whether reactions analogous to Eqs. 15 and 16 can take place if CMP is replaced by MMMC.

\section{The Need for Future Mechanistic Studies}

Before considering what research questions to recommend for future academic and industrial projects, it bears repeating that, based on the literature, highly suitable technologies already exist.

For routine deacidification of acidic books, it has become clear that nonaqueous solution-based systems, using alkoxides or carbonated alkoxides (MMMC, CMP, etc.), provide superior improvements in the useful lifetimes of books relative to other mass deacidification programs (Hubbe et al. 2017; Potthast and Ahn 2017). Clarifications of the manner in which such systems achieve their beneficial effects, such as those as discussed in the present review article, can be expected to support efforts to further improve the performance and fine-tuning of such deacidification systems in future years.

Nevertheless, many potentially fruitful questions remain for future research. Table 6 lists some hypothesis that have been left at least partly unanswered by research up to this point. 
Table 6. Hypotheses in Need of Scientific Research Attention

\begin{tabular}{|c|c|}
\hline Category & Suggested hypothesis \\
\hline \multirow{2}{*}{$\begin{array}{l}\text { Reactions with } \\
\text { acids }\end{array}$} & $\begin{array}{l}\text { Magnesium methoxide (and related chemicals) are able to react directly at } \\
\text { suitable high rates when contacting carboxylic acid species while in } \\
\text { nonaqueous media. Though this hypothesis is supported, in general, by the } \\
\text { evidence presented in this article, there is a need for specific confirmation } \\
\text { with specific reagents and conditions. }\end{array}$ \\
\hline & $\begin{array}{l}\text { Methoxymagnesium methylcarbonate (MMMC) and carbonated magnesium } \\
\text { propoxylate (CMP) are able to react directly at suitable high rates when } \\
\text { contacting carboxylic acid species while in nonaqueous media. Such a } \\
\text { hypothesis needs to be examined in light of the tendency to lower the } \\
\text { reactivity of an alkoxide. }\end{array}$ \\
\hline \multirow{2}{*}{$\begin{array}{l}\text { Reactions with } \\
\text { water }\end{array}$} & $\begin{array}{l}\text { Excessive amounts of water present in paper exposed to dry nonaqueous } \\
\text { solvents such as hexamethyldisiloxane (HMDS) will tend to contaminate the } \\
\text { solvent with dissolved water molecules, leading to premature reaction with the } \\
\text { alkoxide-based agents and likely leading to precipitation of solids within the } \\
\text { bulk liquid. }\end{array}$ \\
\hline & $\begin{array}{l}\text { An optimum level of moisture present in paper to be treated by nonaqueous } \\
\text { solution-based deacidification will tend to promote an even distribution of } \\
\text { alkaline reserve within the paper microstructure, especially if the moisture } \\
\text { level is stoichiometrically matched with the level of alkoxide-based agent, } \\
\text { while considering the amount of carboxylic or other acids present. }\end{array}$ \\
\hline $\begin{array}{l}\text { Reacidification } \\
\text { reactions }\end{array}$ & $\begin{array}{l}\text { There is a concern that the accumulation of acidic species can continue even } \\
\text { after successful deacidification and that such acids may or may not react } \\
\text { efficiently with alkaline reserve materials present in the paper. Is this due to } \\
\text { an inherent incompatibility between the acidic species and alkaline reserve } \\
\text { substances, thus hindering their reaction? Are the acidic and alkaline entities } \\
\text { prevented from coming together while in a dry state? }\end{array}$ \\
\hline \multirow[b]{2}{*}{$\begin{array}{l}\text { Particle } \\
\text { growth }\end{array}$} & $\begin{array}{l}\text { A progressive reaction between alkoxide species and water, which starts out } \\
\text { by producing metal hydroxides, proceeds further (partly by reaction with } \\
\text { additional alkoxide compounds and water) to polymeric or condensed } \\
\text { crystalline forms, depending on the detailed chemistry and conditions. }\end{array}$ \\
\hline & $\begin{array}{l}\text { By combining different metal alkoxide-based reagents in the same } \\
\text { nonaqueous solution deacidification system, there is potential to entrap the } \\
\text { fine particles of one chemical system with a gel-type precipitate of another } \\
\text { chemical system, thus achieving high levels of retention in the paper, as well } \\
\text { as plenty of alkaline reserve material. }\end{array}$ \\
\hline
\end{tabular}

\section{Issues of Optimization and Fine-Tuning}

In parallel with research to address mechanistic questions, as outlined above, one can envision a range of potential developmental investigations aimed at optimizing and improving the performance of treatment processes that will be made available to libraries and other archival institutions in future years. Some of the important issues, based generally on the publications cited in this work, are listed in Table 7. 


\section{Table 7. Issues Likely to be Considered for Further Developmental Work and Optimization of Nonaqueous Solution-based Deacidification Systems}

\begin{tabular}{|l|l|}
\hline Optimization & Selected references \\
\hline $\begin{array}{l}\text { Design of equipment to improve cost-effective, reliable, and safe } \\
\text { treatment of books in a wide range of facilities having different } \\
\text { needs and capabilities. }\end{array}$ & $\begin{array}{l}\text { Eggersdorfer et al. 1990; } \\
\text { Smith 1977; Herren and } \\
\text { Monkewitz 1999 }\end{array}$ \\
\hline $\begin{array}{l}\text { Selecting or developing additional alkaline agents that can } \\
\text { effectively deacidify carboxylic acids and react with residual water } \\
\text { molecules in the paper to yield in situ alkaline reserve, but which } \\
\text { have a slow enough reaction rate with water to avoid stability } \\
\text { problems before the agent reaches the paper surface. }\end{array}$ & $\begin{array}{l}\text { Kelly et al. 1977; } \\
\text { Kaminsky \& Wedinger } \\
1992 ; \text { Raulender et al. } \\
1995 \text { a,b; Clark et al. 1998 }\end{array}$ \\
\hline $\begin{array}{l}\text { Selecting or developing a solvent system (possibly with a co-solvent } \\
\text { or surfactant) that is able to fully dissolve the alkoxide-based agent, } \\
\text { while minimizing any solubilization of common ink components, and } \\
\text { also minimizing adverse environmental impacts. }\end{array}$ & $\begin{array}{l}\text { Smith 1977; Kaminsky \& } \\
\text { Wedinger 1992; Wittekind } \\
1994 b\end{array}$ \\
\hline $\begin{array}{l}\text { Optimizing the target moisture content of books to be treated so as } \\
\text { to achieve full neutralization of acidic species in the paper, a uniform } \\
\text { and ample deposition of alkaline reserve compounds in the paper } \\
\text { microstructure, but no significant excess that might give rise to grit } \\
\text { on the paper or excessive amounts of sediment in the nonaqueous } \\
\text { media trained from the treated books. }\end{array}$ & $\begin{array}{l}\text { Hon 1989; Brandis 1994; } \\
\text { Wittekind 1994a; Clark et } \\
\text { Vogelsanger 2001 }\end{array}$ \\
\hline $\begin{array}{l}\text { Optimization of moisture, temperature, time, and possibly pressure } \\
\text { during the equilibration of treated books in a manner that promotes } \\
\text { completion of neutralization reactions between alkaline reserve } \\
\text { compounds newly deposited in the paper and any residual acidic } \\
\text { species, including inorganic acids. }\end{array}$ & $\begin{array}{l}\text { Optimum conditions have } \\
\text { been established by the } \\
\text { providers of the major } \\
\text { treatment systems. }\end{array}$ \\
\hline $\begin{array}{l}\text { Minimization of costs (capital, labor, and materials) while achieving } \\
\text { all of the other objectives. }\end{array}$ & $\begin{array}{l}\text { Smith 1987; Schwert } \\
1989\end{array}$ \\
\hline
\end{tabular}

\section{Prospects for Conservation Treatments}

In an ideal world, all books acquired for long-term storage and use in libraries would have been printed on archival-grade paper, giving them an expected useful lifetime of many hundreds of years (Shahani and McComb 1987). Or if, by technological circumstance, such a book had been printed on acidic paper, it ideally would have been subjected to an effective deacidification treatment before any significant degradation associated with aging had taken place. These two levels of ideality are often not reached, especially in the case of books printing in the period from about 1850 to 1990 (Hubbe 2005). It follows logically that there should be a large need, as well as a large demand and ample funding for book conservation treatments that add strength to the paper, in addition to slowing down the rate of its further loss of strength. Based on the publication record, it appears that there has been relatively little progress in implementation of strengthenhancing treatments (Blüher and Vogelsanger 2001), especially when compared to the level of implementation of mass-deacidification systems in general.

In cases where books are to be deacidified by use of nonaqueous solution media, it may make sense to first consider ways of strengthening paper based on agents that can be applied to paper likewise from such media. Four such approaches have been disclosed, either in research articles or in patents. These approaches, as described below, are (a) certain alkoxide-based treatments, (b) polyaminoalkylalkoxysilanes, (c) ethylene oxide insitu polymerization, and (d) isocyanate in-situ polymerization. 


\section{Strengthening effects of alkoxide-based treatments}

In principle, if the in-situ growth and precipitation of a metal hydroxide in the presence of alkoxide molecules tends to yield long fibrils of inorganic compounds within a sheet of paper (Smith 2013), then there is a possibility that the paper's strength could be enhanced. A gel-like nature of the deposited material (Raulender et al. 1995b; Kordas 2000; Urlaub et al. 2000; Ranjit and Klabunde 2005) can be regarded as contributing evidence of such fine fibrillar nature of the inorganic material. Such a mechanism finds partial support in observations showing increased paper strength following certain alkoxide-based deacidification treatments. According to some reports, treatment of paper with the so-called dual alkoxide (a combination of magnesium ethoxide and titanium ethoxide) has been found to contribute an immediate strengthening effect (Wittekind 1994a; Porck 1996). Scott (1987) reported a small increase in strength of some books deacidified by the Wei T'o system. Wittekind (1994a) attributed the observed favorable effects on strength to the ability of $\mathrm{TiO}_{2}$, formed by the reaction of titanium ethoxide with water, to form hydrogen bonds with cellulose surfaces. However, the observed positive impacts on strength were probably too small to be regarded as having value.

There are other reports showing immediate decreases in paper strength upon treatment with alkoxide-based agents. For instance, Green and Leese (1991) reported low strength of books treated by MMMC compared to control paper from the same book. Experiments reported by Porck (1996) likewise showed a loss of strength, rather than a strength improvement, following dual alkoxide deacidification. In light of such conflicting reports, it appears there is a need for more focused research, not only on whether but also on how various alkoxide-based deacidification treatments can affect different strength properties of paper, even before accelerated aging.

\section{Strengthening effects of polyaminoalkylalkoxysilanes}

A process based on polyaminoalkylalkoxysilanes has been developed to provide both deacidification and strengthening simultaneously (Ipert et al. 2006; Dupont et al. 2010; Souguir et al. 2011, 2012; Piovesan et al. 2014, 2017). The treatment was found to increase both the tensile strength and the folding endurance, including when paper sheets were evaluated after aging. The solvent employed in the cited work was HMDS, i.e. the same solvent employed in the Batelle mass deacidification system. The deacidification effect, which can be attributed to the amino functionality within the polymerized silane material, was confirmed by increases in the alkaline reserve content of treated paper (Piovesan et al. 2014). Dupont et al. (2010) suggested that the mechanism of strengthening involves hydrogen bonding, consistent with the development of strength in ordinary paper. The greatest strength improvements were observed when paper was treated to form a copolymer of two di-alkoxyiloxanes, one with and one without an amine functionality (Piovesan et al. 2014).

\section{Ethylene oxide polymerization for strength enhancement}

As described by Smith (1972a, 1987, 2012, 2013), brittle paper can be effectively strengthened by treatment with ethylene oxide gas in the course of or immediately following alkoxide-based deacification. The polymerization of the gas appears to be catalyzed by magnesium alkoxide-related compounds present in paper during or after its deacidification (Smith 1987). Despite evidence of effectiveness in overcoming brittleness 
and increasing various strength parameters, little commercial interest in such technology has been shown (Smith 2012). In principle, after some additional construction, the described strengthening treatment could be applied using the same chambers and vacuum equipment as employed for the mass deacidification.

\section{Urethane polymerization for paper strengthening}

Wittekind (1996) claimed a treatment with a combination of metal organic compounds, methylcellulose, and 2,4-toluene diisocyanate dissolved as a solution in hexamethylenedsiloxane, the same solvent used in the Batelle Papersave deacidification system. The metal organic compound can be an organo-tin compound that catalyzes polymerization of the diisocyanate while it is present within paper sheets. Reaction of the diisocyanate with a polyol, such as methylcellulose, can be expected to create multiple urethane linkages. Presumably such in-situ polymerization can yield a cross-linked polymer. The high compatibility of methylcellulose with the cellulose fiber surfaces within paper can be regarded as being favorable for development of paper strength through such a bonding mechanism.

\section{Strengthening based on moistening of deacidified books}

An earlier review article (Hubbe et al. 2017) considered various options involving the partial or substantial humidification or moistening of books for the purpose of encouraging completion of neutralization reactions between acidic species present in the paper and alkaline reserved compounds. A side benefit, as mentioned in the cited review article, is that various moisturizing treatments, followed by re-drying, can provide additional options for the strengthening of paper within books that have been subjected to aging and embrittlement.

\section{CLOSING COMMENTS}

This review of the literature has gathered together information regarding nonaqueous solution-based deacidification systems, which generally employ metal alkoxides and related carbonated compounds as the active agents. In addition to showcasing evidence of the high efficacy of such treatments, relative to the useful lifetimes of treated books, a basic explanation of how those systems work, in a chemical sense, is starting to come together. Areas of need for additional research have been noted, both in terms of mechanistic studies and for optimization and improvement of the performance of implemented deacidification systems.

Based on the discussion of research cited in this article, alkoxide-based deacidification systems, employing nonaqueous solution, work by direct neutralization of carboxylic acids in the paper, starting during the immersion of the paper items in the nonaqueous solution. The fact that the active agent is dissolved in a dry, nonaqueous solvent allows it to be transported into fine pores and cell walls of the fibers within the paper article to be treated. Alkoxide-based agents are likely to react directly with carboxylic acids present within paper's microstructure.

Reaction of residual water molecules (perhaps in the range of about 0.5 to $1.0 \%$ by mass) in the paper provides a mechanism by which to achieve a relatively uniform 
deposition of alkaline reserve material throughout the pores within the paper. Also, some known strategies for the strengthening of paper, using treatments in conjunction with or following the nonaqueous solution-based deacidification, have the potential to be further developed and implemented.

Library and archival systems, almost all of which face serious annual losses in the value of their holdings due to embrittlement of those items that had been printed on acidic paper, have the opportunity to achieve long-term benefits by deacidification of those items. The acid hydrolysis taking place within those books or other archived materials can be greatly slowed down. Our understanding of how those treatments work is getting clearer, which provides additional support for a recommendation for prompt and widespread implementation of such treatments.

\section{ACKNOWLEDGEMENTS}

The work of Dr. Hubbe was supported by the endowment fund from the Buckman Foundation. The authors greatly appreciate the time and effort from the following people who gave input and suggested corrections: Anne-Laurence Dupont, Natural History Museum, Ctr. Rech. Conservat. Documents Graph., Minist. Culture \& Commun., France; Gerhard Banik, Vienna, Austria; Spiros Zervos, Department of Archival, Library \& Information Studies, University of West Attica, Greece; Xiwen Zhang, Zhejiang Univ., Dept. Materials Science \& Engineering, Hangzhou, China; and Thorsten Allscher, Bayerische Staatsbibliothek, IBR, Germany.

\section{REFERENCES CITED}

Ahn, K., Banik, G., Henniges, U., and Potthast, A. (2012a). "Nachhaltigkeit in der Massenentsäuerung von Biblioteksgut," in: Eine Zukunft für Saures Papier (A Future for Acid Paper), R. Altenhöner, A. Blüher, A. Mälck, E. Niggemann, A. Potthast, and B. Schneider-Kemf (eds.), Vittorio Klostermann, Frankfurt am Main, pp. 29-81.

Ahn, K., Banik, G., and Potthast, A. (2012b). "Sustainability of mass deacidification. Part II. Evaluation of alkaline reserve," Restaurator 33(1), 48-75. DOI: 10.1515/res-20120003

Ahn, K., Henniges, U., Banik, G., and Potthast, A. (2012c). "Is cellulose degradation due to $\beta$-elimination processes a threat in mass deacidification of library books?," Cellulose 19(4), 1149-1159. DOI: 10.1007/s10570-012-9723-3

Ahn, K., Henniges, U., Blüher, A., Banik, G., and Potthast, A. (2011). "Sustainability of mass deacidification. Part I: Concept, selection of sample books and $\mathrm{pH}$ determination," Restaurator 32(3), 193-222. DOI: 10.1515/rest.2011.010

Ahn, K., Rosenau, T., and Potthast, A. (2013). "The influence of alkaline reserve on the aging behavior of book papers," Cellulose 20, 1989-2001. DOI: 10.1007/s10570-0139978-3

Ambreen, S., Gupta, K., Singh, S., Gupta, D. K., Daniele, S., Pandey, N. D., and Pandey, A. (2013). "Synthesis and structural characterization of some titanium butoxides 
modified with chloroacetic acids," Transition Metal Chem. 38(8), 835-841. DOI: 10.1007/s11243-013-9756-y

Andres, H. (2006). "Papersave Swiss - effects on fungi," in: Save Paper, A. Blüher, G. Grossenbacher, and G. Banik (eds), Swiss National Library, Bern, pp. 164-175. ISBN 3-9523188-1-7, ISBN 978-3-9523188-1-2, online: www.snl.admin.ch.

Andres, H., Blüher, A., Grossenbacher, G., Reist, M., Vogelsanger, B., and Wälchli, M. (2008). "The Papersave Swiss - Process quality control and efficacy," Restaurator 28(1), 3-28. DOI: 10.1515/rest.2008.002

Area, M. C., and Cheradame, H. (2011). "Paper aging and degradation: Recent findings and research methods," BioResources 6(4), 5307-5337. DOI:

10.15376/biores.6.4.5307-5337

Arney, J. S., Jacobs, A. J., and Newman, R. (1979). "The influence of deacidification on the deterioration of paper," J. Am. Inst. Conserv. 19(1), 34-41. DOI: $10.2307 / 3179571$

Badr, O., and Probert, S. D. (1993). "Environmental impacts of atmospheric nitrousoxide," Applied Energy 44(3), 197-231. DOI: 10.1016/0306-2619(93)90018-K

Banik, G. (2005). "Mass deacidification technology in Germany and its quality control," Restaurator 26(1), 63-75. DOI: 10.1515/rest.2005.63

Banik, G., and Brückle, I. (eds.). (2011). Paper and Water: A Guide for Conservators, Elsevier, Butterworth-Heinemann, Amsterdam, Boston, Oxford.

Banik, G., Doering, T., and Hähner, U. (2006). "Current efforts to establish an effective quality management for mass deacidification," in: Save Paper! Mass Deacidification, Today's Experiences, Tomorrow's Perspectives: Papers given at the international conference, 15-17 February. 2006, s. 94-110.

Bastone, S., Martino, D. F. C., Renda, V., Saladino, M. L., Poggi, G., and Caponetti, E. (2017). "Alcoholic nanolime dispersion obtained by the insolubilisation-precipitation method and its application for the deacidification of ancient paper," Colloids Surf. A 513, 241-249. DOI: 10.1016/j.colsurfa.2016.10.049

Baty, J. W., Maitland, C. L., Minter, W., Hubbe, M. A., and Jordan-Mowery, S. K. (2010). "Deacidification for the conservation and preservation of paper-based works: A review," BioResources 5(3), 1955-2023. DOI: 10.15376/biores.5.3.1955-2023

Baynes-Cope, A. D. (1969). "Non-aqueous deacidification of documents," Restaurator 1(1), 2-9.

Becker, M., Meyer, F., Jeong, M. J., Ahn, K., Henniges, U., and Potthast, A. (2016). "The museum in a test tube - Adding a third dimension to the evaluation of the impact of volatile organic acids on paper," Polym. Degrad. Stabil. 130, 109-117. DOI: 10.1016/j.polymdegradstab.2016.05.026

Blüher, A., and Vogelsanger, B. (2001). "Mass deacidification of paper," Chimia 55(11), 981-989.

Boyle, T. J., Alam, T. M., Tafoya, C. J., and Scott, B. L. (1998). "Formic acid modified $\mathrm{Ti}\left(\mathrm{OCHMe}_{2}\right)_{4}$. Syntheses, characterization, and X-ray structures of $\mathrm{Ti}_{4}\left(\mu_{4}-\mathrm{O}\right)(\mu-$ $\mathrm{O})(\mathrm{OFc})_{2}(\mu-\mathrm{OR})_{4}(\mathrm{OR})_{6}$ and $\mathrm{Ti}_{6}\left(\mu_{3}-\mathrm{O}\right)_{6}(\mathrm{OFc})_{6}(\mathrm{OR})_{6}\left(\mathrm{OFc}=\mathrm{O}_{2} \mathrm{CH} ; \mathrm{OR}=\mathrm{OCHMe}_{2}\right)$," Inorg. Chem. 37(21), 5588-5594. DOI: 10.1021/ic980601f

Boyle, T. J., Ottley, L. A. M., and Rodriguez, M. A. (2005). "Structurally characterized carboxylic acid modified zirconium alkoxides for the production of zirconium oxide thin films," Polyhedron 24(13), 1727-1738. DOI: 10.1016/j.poly.2005.05.005 
Boyle, T. J., Tribby, L. J., and Bunge, S. D. (2006). "Synthesis and structural characterization of a series of carboxylic acid modified cerium(III) alkoxides," Eur. $J$. Inorg. Chem. 22, 4553-4563. DOI: 10.1002/ejic.200600616

Boyle, T. J., Tyner, R. P., Alam, T. M., Scott, B. L., Ziller, J. W., and Potter, B. G. (1999). "Implications for the thin-film densification of $\mathrm{TiO}_{2}$ from carboxylic acidmodified titanium alkoxides. Syntheses, characterizations, X-ray structures of $\mathrm{Ti}_{3}\left(\mu_{3}-\right.$ $\mathrm{O})\left(\mathrm{O}_{2} \mathrm{CH}\right)_{2}(\mathrm{ONep})_{8}, \mathrm{Ti}_{3}\left(\mu_{3}-\mathrm{O}\right)\left(\mathrm{O}_{2} \mathrm{CMe}\right)_{2}(\mathrm{ONep})_{8}, \mathrm{Ti}_{6}\left(\mu_{3}-\mathrm{O}\right)_{6}\left(\mathrm{O}_{2} \mathrm{CCHMe}_{2}\right)_{6}(\mathrm{ONep})_{6}$, $\left[\mathrm{Ti}\left(\mu-\mathrm{O}_{2} \mathrm{CCMe}_{3}\right)(\mathrm{ONep})_{3}\right]_{2}$, and $\mathrm{Ti}_{3}\left(\mu_{3}-\mathrm{O}\right)\left(\mathrm{O}_{2} \mathrm{CCH}_{2} \mathrm{CMe}_{3}\right)_{2}(\mathrm{ONep})_{8}(\mathrm{ONep}=$ $\left.\mathrm{OCH}_{2} \mathrm{CMe}_{3}\right)$," J. Amer. Chem. Soc. 121(51), 12104-12112. DOI: 10.1021/ja992521w

Brandis, L. (1994). "Summary and evaluation of the testing sponsored by the Library of Congress of books deacidified by the FMC, AKZO and Wei To mass deacidification processes," Restaurator 15(2), 109-127. DOI: 10.1515/rest.1994.15.2.109

Brückle, I., and Banik, G. (2011a). "The introduction of water into paper," in: Paper and Water: A Guide for Conservators, G. Banik and I. Brückle (eds.), Elsevier, Butterworth-Heinemann, Amsterdam, Boston, Oxford, pp. 255-288.

Brückle, I., and Banik, G. (2011b). "Drying paper in convervation practice," in: Paper and Water: A Guide for Conservators, G. Banik and I. Brückle (eds.), Elsevier, Butterworth-Heinemann, Amsterdam, Boston, Oxford, pp. 389-418.

Bukovský, V. (2005). "The analysis of alkaline reserve in paper after deacidification," Restaurator 26(4), 265-275. DOI: 10.1515/REST.2005.265

Burgess, H., D., and Kaminska, E. (1991). "Evaluation and comparison of commercial mass-deacidification processes. Part 1: Project planning and selection of materials," Book and Paper Group Annual 10, http:/cool.conservationus.org/coolaic/sg/bpg/annual/v10/bp10-04.html

Buyuktas, B. S. (2006). "Investigation of the complexation and hydrolysis-condensation of titanium(IV) n-butoxide [Ti(OBun $\left.)_{4}\right]$ with some unsaturated mono and dicarboxylic acids," Transition Metal Chem. 31(6), 786-791. DOI: 10.1007/s11243006-0070-9

Calvini, P., Gorassini, A., and Merlani, A. L. (2007). "Autocatalytic degradation of cellulose paper in sealed vessels," Restaurator 28(1), 47-54. DOI:

10.1515/rest.2007.47

Carnes, C. L., and Klabunde, K. J. (2000). "Synthesis, isolation, and chemical reactivity studies of nanocrystalline zinc oxide," Langmuir 16(8), 3764-3772. DOI: 10.1021/la991498p

Cedzova, M., Gallova, I., and Katuscak, S. (2006). "Patents for paper deacidification," Restourator - International Journal for the Preservation of Library and Archival Material 27(1), 35-45. DOI: 10.1515/REST.2006.35

Clark, R. J. H., Gibbs, P. J., and Jarjis, R. A. (1998). "An investigation into the deacidification of paper by ethoxymagnesium ethylcarbonate," J. Mater. Chem. 8(12), 2685-2690. DOI: 10.1039/a804453h

Couture, R. (1999). "Challenges in mass deacidification," Natl. Library News 31(7-8), 810.

Daniels, V. D. (1996). “The chemistry of paper conservation,” Chem. Soc. Rev. 25(3), 179-186. DOI: 10.1039/cs9962500179

De Leeuw, G. P. G. M. (1988a). "Preserving paper sheets or webs with thymol and methyl magnesium methyl carbonate," Eur. Pat. 88200608 Appl. 880331 
De Leeuw, G. P. G. M. (1988b). "Preserving paper sheets or webs and device for carrying out that purpose," Eur. Pat. 0285227 A1

Diao, Y. L., Walawender, W. P., Sorensen, C. M., Klabunde, K. J., and Ricke, T. (2002). "Hydrolysis of magnesium methoxide. Effects of toluene on gel structure and gel chemistry," Chem. Mater. 14(1), 362-368. DOI: 10.1021/cm010708s

Dupont, A.-L., Barthez, J., Jerosch, H., and Lavédrine, B. (2002). "Testing CSC Book Saver [registered trademark], a commercial deacidification spray," Restaurator 23(1), 39-47. DOI: 10.1515/REST.2002.39

Dupont, A. L., Lavedrine, B., and Cheradame, H. (2010). "Mass deacidification and reinforcement of papers and books. VI - Study of aminopropylmethyldiethoxysilane treated papers," Polym. Degrad. Stabil. 95(12), 2300-2308. DOI: 10.1016/j.polymdegradstab.2010.09.002

Eggersdorfer, R., Schwerdt, P., and Wittekind, J. (1990). "Process and device for nonpolluting mass deacidification of books and other paper products," US Patent $5,120,500$, assigned to the Battelle Institute.

Fengel, D., and Wegener, G. (1984). Wood: Chemistry, Ultrastructure, Reactions, Walter de Gruyter, Berlin, New York.

Finkbeiner, H. L., and Stiles, M. (1963). "Chelation as a driving force in organic reactions. 4. Synthesis of alpha-nitro acids by control of carboxylationdecarboxylation equilibrium," J. Amer. Chem. Soc. 85, 616-622. DOI: 10.1021/ja00888a031

Fric, H., Jupa, M., and Schubert, U. (2006). "The solid-state structures of a non-hydrated yttrium carboxylate and a yttrium carboxylate hemihydrate obtained by reaction of yttrium alkoxides with carboxylic acids," Monatshefte Chemie 137(1), 1-6. DOI: 10.1007/s00706-005-0400-1

Gibert Vives, J. M., Dagà Monmany, J. M., and Areal Guerra, R. (2004). "Nondestructive method for alkaline reserve determination in paper," Diffuse Reflectance Infrared Fourier Transform Spectroscopy 25(1), 47-67.

Green, L. R., and Leese, M. (1991). "Nonaqueous deacidification of paper with methyl magnesium carbonate," Restaurator 12(3), 147-162.

Greve, K., Nielsen, E., and Ladefoged, O. (2008). "Toxic effects of siloxanes: Group evaluation of D3, D4, D5, D6 and HMDS in order to set a health based quality criterion in ambient air," Toxicology Let. 180(1)

Henniges, U., Schiehsser, S., Ahn, K., Hofinger, A., Geschke, A., Potthast, A., and Rosenau, T. (2012). "On the structure of the active compound in mass deacidification of paper," Holzforschung 66, 447-450. DOI 10.1515/HF.2011.174

Henniges, U., Schröter, K., and Potthast, A. (2005). "Tapeten und Kupferfraß,” in: Überlegungen zur Durchführung einer Restaurierungsbehandlung, Band 2. Gerhard Banik, Wolfgang Wächter (eds.), BWV Berliner Wissenschaftsverlag, Berlin.

Herren, C., and Monkewitz, M. (1999). "Wirkstoff und Vorrichtung zur Entsäuerung von Schriftgut," ["Device for the deacidification of printed matter"], WO 1999051818 A1; [EP 1084299 B1]

Hey, M. (1981). "The washing and stabilization of iron gall inks," Restaurator 2, 24-44.

Hofmann, R., and Wiesner, H.-J. (2015). "Empfehlung zur Prüfung des Behandlungserfolgs von Entsäuerungsverfahren für säurehaltige Druck- und 
Schreibpapiere," in: Bestandeshaltung in Archiven und Biblioteken, DIN e.V (Eds.), $5^{\text {th }}$ Ed., Beuth, Berlin, Wien, Zurich, ISBN 978-3-410-25411-9.

Hon, D. N.-S. (1989). "Critical evaluation of mass deacidification processes for book preservation," In: Historic Textile and Paper Materials. II, Zeronian, S. H., and Needles, H. L. (eds.), American Chemical Society, Washington, DC. DOI: 10.1021/bk-1989-0410.ch002

Hrivnak, J., Tolgyessy, P., Figedyova, S., and Katuscak, S. (2009a). “A solid-phase microcolumn extraction method for the analysis of acetic acid and furfural emitted from paper," Chromatographia 70(3-4), 619-622. DOI: 10.1365/s10337-009-1193-x

Hrivnak, J., Tolgyessy, P., Figedyova, S., and Katuscak, S. (2009b). "Solid phase microcolumn extraction and gas chromatography-mass spectrometry identification of volatile organic compounds emitted by paper," Talanta Journal 80(2), 400-402. DOI: 10.1016/j.talanta.2009.06.035

Hubbe, M. A. (2005). "Acidic and alkaline sizings for printing, writing, and drawing papers," The Book and Paper Group Annual 23, 139-151.

Hubbe, M. A. (2006). "Bonding between cellulosic fibers in the absence and presence of dry-strength agents - A review," BioResources 1(2), 281-318. DOI: 10.15376/biores.1.2.281-318

Hubbe, M. A. (2015). "Oops, I thought that those books had been deacidified," BioResources 10(4), 6305-6309. DOI: 10.15376/biores.10.4.6305-6309

Hubbe, M. A., Smith, R. D., Zou, X. J., Katuscak, S., Potthast, A., and Ahn, K. J. (2017). "Deacidification of acidic books and paper by means of non-aqueous dispersions of alkaline particles: A review focusing on completeness of the reaction," BioResources 12(2), 4410-4477. DOI: 10.15376/biores.12.2.Acidic_Books_Hubbe

Ipert, S., Dupont, A. L., Lavedrine, B., Begin, P., Rousset, E., and Cheradame, H. (2006). "Mass deacidification of papers and books. IV - A study of papers treated with aminoalkylalkoxysilanes and their resistance to ageing," Polym. Degrad. Stabil. 91(12), 3448-3455. DOI: 10.1016/j.polymdegradstab.2006.04.033

ISO (1994) ISO 10716:1994 Paper and board, "Determination of alkali reserve," International Organization for Standardization.

ISO (2016). ISO/TS 18344:2016, "Effectiveness of paper deacidification processes," International Organization for Standardization.

Jablonsky, M., Hrobonova, K., Katuscak, S., Lehotay, J., and Botkova, M. (2012). "Formation of acetic and formic acid in unmodified and modified papers during accelerated ageing," Cellulose Chem. Technol. 46(5-6), 331-340.

Jablonsky, M., Holubkova, S., Kazikova, J., Botkova, M., Haz, A., and Bajzikova, M. (2013). "The treatment of acid newsprint paper: Evaluation of treatment by $\mathrm{MgO}$ or by a mixture of $\mathrm{MgO}$ and methyl methoxy magnesium carbonate," Wood Research 58(2), 151-164.

Jaegers, E., Seidel, A., and Pottkamper, K. (1994). "Process for the stabilization of ethanolic ethylmagnesium carbonate solution," US Pat. 5,326,897 A

Jezewska, E., Kurkowska, J., Zaleska, K., and Zatorska, A. (2013). "Studies on watercolour deacidification by means of the Bookkeeper preparation," in: Optics for Arts, Architecture, and Archaeology IV, L. Pezzati and P. Targowski (eds.), Vol. 8790, article no. UNSP 879013. DOI: 10.1117/12.2020347 
Kaminska, E. M., and Burgess, H. (1994). "Evaluation of commercial mass deacidification processes: AKZO-DEZ, Wei T'o, and FMC-GM3 - Phase 2. New and artificially aged modern papers," Ottowa: Canadian Conservation Inst.

Kaminsky, C. W., and Wedinger, R. L. (1992). "Mass treatment of cellulosic materials," US Pat. 5,104,997.

Katuscak, S., Jablonsky, M., and Holubkova, S. (2012). "Comparative evaluation of deacidification processes," in: Eine Zukunft für Saures Papier, Altenhöner, R., Blüher, A., Mälck, A., Niggemann, E., Potthast, A., and Schneider-Kempf, B. (eds.), Vittorio Klostermann, Frankfurt am Main, pp. 149-176.

Katuscak, S., Vizarova, K., Bakos, D., Vrska, M., and Cedzova, M. (2007). "Multicomponent mixture for stabilization and strengthening of paper" (Multikomponentná zmes určená na stabilizáciu a spevňovanie papierových hárkov). SK Patent 286410.

Kellerman, L. S. (1999). "Combating whole-book deterioration: The rebinding \& mass deacidification program at the Penn State University Libraries," Library Resources Tech. Serv. 43(3), 170-177. DOI: 10.5860/1rts.43n3.170

Kelly, G. B. (1976). "Composition for use in deacidification of paper,” US Pat. $3,939,091$.

Kelly, G. B., Jr., and Fowler, S. (1978). "Penetration and placement of alkaline compounds in solution-deacidified paper," J. Am. Inst. Conserv. 17(2), 33-43. DOI: $10.2307 / 3179754$

Kelly, G. B., Jr., Tang, L. C., and Krasnow, M. K. (1977). "Methyl magnesium carbonate - An improved nonaqueous deacidification agent," Adv. in Chem. Ser. (ACS) 164 (Preserv. of Paper \& Textiles Symp., San Francisco, Aug. 1976), 62-71.

Khairallah, F., and Glisenti, A. (2007). "Synthesis, characterization and reactivity study of nanoscale magnesium oxide," J. Molec. Catal. A - Chem. 274(1-2), 137-147. DOI: 10.1016/j.molcata.2007.04.039

Kickelbick, G., Feth, M. P., Bertagnolli, H., Puchberger, M., Holzinger, D., and Gross, S. (2002). "Formation of organically surface-modified metal oxo clusters from carboxylic acids and metal alkoxides: A mechanistic study," J. Chem. Soc. Dalton Trans. 20, 3892-3898. DOI: 10.1039/b207994a

Kolar, J., Strlič, M., Novak, G., and Philar, B. (1998). “Aging and stabilization of alkaline paper," J. Pulp Paper Sci. 24(3), 89-94.

Kordas, G. (2000). "Sol-gel preparation of MgO fibers," J. Mater. Chem. 10(5), 1157 1160. DOI: $10.1039 / \mathrm{b} 0010150$

Leiner, L. H., and Kifer, E. W. (1995). "Deacidification of cellulose-based materials using perfluorinated carriers," US Pat. 5,409,736

Lichtenberger, R., and Schubert, U. (2010). "Chemical modification of aluminium alkoxides for sol-gel processing," J. Mater. Chem. 20(42), 9287-9296. DOI: 10.1039/c0jm00993h

Lienardy, A. (1994). "Evaluation of seven mass deacidification treatments," Restaurator 15(1), 1-25. DOI: 10.1515/rest.1994.15.1.1

Liers, J., and Schwerdt, P. (1995). "The Battelle mass deacidification process equipment and technology," Restaurator 16, 1-9. DOI: 10.1515/rest.1995.16.1.1 
MacInnes, A. N., and Barron, A. R. (1992). "Spectroscopic evaluation of the efficacy of two mass deacidification processes for paper," J. Mater. Chem. 2(10), 1049-1056. DOI: $10.1039 / \mathrm{JM} 9920201049$

Mathur, S., and Mehrotra, R. C. (1967). "Organic derivatives of germanium. 6. Reactions of organogermanium alkoxides with carboxylic acids," J. Organometallic Chem. 7(2), 227-231. DOI: 10.1016/S0022-328X(00)91071-4

Meerwein, H., and Bersin, T. (1929). "Untersuchung über Metallalkoholate und Orthosäureester. I. Über Alkoxosäuren und ihre Salze,” Ann. Chemie 476, 113-150. DOI: 10.1002/jlac.19294760105

Menart, E., de Bruin, G., and Strlič, M. (2014). "Effects of $\mathrm{NO}_{2}$ and acetic acid on the stability of historic paper," Cellulose 21(5), 3701-3713. DOI: 10.1007/s10570-0140374-4

Morrow, G. (1988). "Mass deacidification: Operational experience at the National Archives and the National Library of Canada," Paper Conservator Conf. 12, 40-46. DOI: 10.1080/03094227.1988.9638561

Piovesan, C., Dupont, A. L., Fabre-Francke, I., Fichet, O., Lavedrine, B., and Cheradame, H. (2014). "Paper strengthening by polyaminoalkylalkoxysilane copolymer networks applied by spray or immersion: A model study," Cellulose 21(1), 705-715. DOI: 10.1007/s10570-013-0151-9

Piovesan, C., Fabre-Francke, I., Dupont, A. L., Fichet, O., Paris-Lacombe, S., Lavedrine, B., and Cheradame, H. (2017). "The impact of paper constituents on the efficiency of mechanical strengthening by polyaminoalkylalkoxysilanes," Cellulose 24(12), 56715684. DOI: 10.1007/s10570-017-1513-5

Poggi, G., Giorgi, R., Mirabile, A., Xing, H. P., and Baglioni, P. (2017). “A stabilizerfree non-polar dispersion for the deacidification of contemporary art on paper," $J$. Cultural Heritage 26, 44-52. DOI: 10.1016/j.culher.2017.02.006

Polovka, M., Polovkova, J., Vizarova, K., Kirschnerova, S., Bielikova, L., and Vrska, M. (2006). "The application of FTIR spectroscopy on characterization of paper samples, modified by Bookkeeper process," Vibrational Spectroscopy 41(1), 112-117. DOI: 10.1016/j.vibspec.2006.01.010

Porck, H. J. (1996). Mass Deacidification. An Update on Possibilities and Limitations, European Commission on Preservation and Access, Amsterdam; Commission on Preservation and Access, Washington, $51 \mathrm{pp}$.

Potthast, A., and Ahn, K. (2017). "Critical evaluation of approachs toward mass deacidification of paper by dispersed particles," Cellulose 24, 323-332. DOI: 10.1007/s10570-016-1112-x

Pronha, M. (2016). "Toxicity and the biological role of methanol and ethanol: Current view," Biomed. Papers - Olomouc 160(1), 54-63. DOI: 10.5507/bp.2015.023

Ramin, M., Andres, H., Blüher, A., Reist, M., and Wälchli, M. (2009). "Paper deacidification - A comparative study," J. Paper Conservation 10(3), 17-25.

Ranjit, K. T., and Klabunde, K. J. (2005). "Solvent effects in the hydrolysis of magnesium methoxide, and the production of nanocrystalline magnesium hydroxide. An aid in understanding the formation of porous inorganic materials," Chem. Mater. 17(1), 65-73. DOI: $10.1021 / \mathrm{cm} 040360 \mathrm{~b}$ 
Rauleder, H., Standke, B., Kotzsch, J., and Schork, R. (1995a). "Storage-stable solutions of carbonated magnesium ethylate in ethanol and their preparation for use," US Pat. $5,456,801$

Rauleder, H., Standke, B., Kotzsch, H.-J., and Schork, R. (1995b). “Storage-stable solutions of carbonated magnesium methoxide in methanol and their preparation for use," US Pat. 5,468,705

Ravindra, K., Sokhi, R., and Van Grieken, R. (2008). "Atmospheric polycyclic aromatic hydrocarbons: Source attribution, emission factors and regulation," Atmos. Environ. 42(13), 2895-2921. DOI: 10.1016/j.atmosenv.2007.12.010

Ravishankara, A. R., Turnipseed, A. A., Jensen, N. R., Barone, S., Mills, M., Howard, C. J., Solomon, S. (1994). "Do hydrofluorocarbons destroy stratospheric ozone?," Science 263(5143), 71-75. DOI: 10.1126/science.263.5143.71

Reist, M. (2006). "Papersave Swiss process, operation, and quality," in: Save Paper , A. Blüher, G. Grossenbacher, and G. Banik (eds), Swiss National Library, Bern, pp. 153162. ISBN 3-9523188-1-7, ISBN 978-3-9523188-1-2, online: www.snl.admin.ch.

Saoud, K. M., Saeed, S., Al Soubaihi, R., Samara, A., Ibala, I., El Ladki, D., and Ezzeldeen, O. (2018). "Application of $\mathrm{Mg}(\mathrm{OH})_{2}$ nanosheets for conservation and restoration of precious documents and cultural archives," BioResources 13(2), 32593274. DOI: 10.15376/biores.13.2.3259-3274

Schwerdt, P. (1989). "Mass deacidification procedures for libraries and archieves: State of development and perpsectives for implementation in the Federal Republic of Germany," Commission on Preservation and Access, Report, Sept., 1785 Massachusetts Ave. NW, Suite 313, Washington, DC 20036

Scott, M. (1987). "Mass deacidification at the National Library of Canada," Restaurator 8(2/3), 94-99. DOI: 10.1515/rest.1987.8.2-3.94

Shahani, C. J., and Harrison, G. (2002). "Spontaneous formation of acids in the natural aging of paper," in: Proceedings of Works of Art on Paper, Books, Documents and Photographs: Techniques and Conservation, V. Daniels, A. Donnithorne, and P. Smith (eds.), IIC, Baltimore, pp.189-192. DOI: 0.1179/sic.2002.47.s3.039

Shahani, C. J., and McComb, R. E. (1987). "A clarification on specifications for archival paper," TAPPI J. 70(9), 128-128.

Sistach, M., Marin, E., and Garcia, J. (2017). "Evaluation of alkaline compounds used for deacidification and simultaneous lining of extremely degraded manuscripts," Restaurator 38(3), 249-272. DOI: 10.1515/res-2016-0034

Smith, R. D. (1969). "Paper impermanence as a consequence of $\mathrm{pH}$ and storage conditions," The Library Quarterly 39(2), 153-195. DOI: 10.1086/619740

Smith, R. D. (1970). Nonaqueous Deacidification of Paper and Books, Univ. Chicago, Chicago, IL, 295 pp.

Smith, R. D. (1972a). "Preserving cellulose materials through treatment with alkylene oxides," US Pat. 3,676,055.

Smith, R. D. (1972b). “Treatment of cellulosic materials," US Pat. 3,676,182.

Smith, R. D. (1977). "Design of a liquefied gas mass deacidification system for paper and books," Adv. Chem. Ser. (ACS) 164, 149-158. DOI: 10.1021/ba-1977-0164.ch011

Smith, R. D. (1979). "Progress in mass deacidification at the Public Archives," Canadian Library Journal 36(6), 325-332.

Smith, R. D. (1982). “Treatment of cellulosic materials," US Pat. 4,318,963 
Smith, R. D. (1987). "Deacidifying library collections: Myths and realities," Restaurator 8(2/3), 69-93. DOI: 10.1515/rest.1987.8.2-3.69

Smith, R. D. (1989). “Treatment of cellulosic materials," US Pat. 4,860,685.

Smith, R. D. (1992). "Disaster recovery - Problems and procedures," J. Internat. Fed. Lib. Assoc. 18(1), 13-24. DOI: 10.1177/034003529201800106

Smith, R. D. (2000). "Process of preserving paper," US Pat. 6,071,475

Smith, R. D. (2012). "Wei T’o Paperguard: Comprehensive deacidifying, stabilizing and strengthening of paper," Mass deacidification session, BPG \& RATS, AIC 2012 Annual Meeting, Albuquerque, NM.

Smith, R. D. (2013). "Deacidification treatments of printed cellulosic materials," US Pat. $0302524 \mathrm{AI}$

Solomon, S. (1999). "Stratospheric ozone depletion: A review of concepts and history," Rev. Geophysics 37(3), 275-316. DOI: 10.1029/1999RG900008

Souguir, Z., Dupont, A. L., de Lacaillerie, J. B. D., Lavedrine, B., and Cheradame, H. (2011). "Chemical and physicochemical investigation of an aminoalkylalkoxysilane as strengthening agent for cellulosic materials," Biomacromol. 12(6), 2082-2091. DOI: $10.1021 / \mathrm{bm} 200371 \mathrm{u}$

Souguir, Z., Dupont, A. L., Fatyeyeva, K., Mortha, G., Cheradame, H., Ipert, S., and Lavedrine, B. (2012). "Strengthening of degraded cellulosic material using a diamine alkylalkoxysilane," RSC Advances 2(19), 7470-7478. DOI: 10.1039/c2ra20957h

Stengl, V., Bakardjieva, S., Marikova, M., Bezdicka, P., and Subrt, J. (2003). "Magnesium oxide nanoparticles prepared by ultrasound enhanced hydrolysis of $\mathrm{Mg}$ alkoxides," Mater. Lett. 57(24-25), 3998-4003. DOI: 10.1016/S0167577X(03)00254-4

Strlič, M., Kolar, J., Selih, V. S., Kocas, D., and Pihlar, B. (2003). "A comparative study of several transition metals in Fenton-like reaction systems at circum-neutral $\mathrm{pH}$," Acta Chimica Slovenica 50(4), 619-632.

Sundholm, F., and Tahvanainen, M. (2003). "Paper conservation using aqueous solutions of calcium hydroxide/methyl cellulose - 1. Preparation of the solution," Restaurator 24(1), 1-17. DOI: 10.1515/REST.2003.1

Tephly, T. R. (1991). “The toxicity of methanol," Life Sciences 48(11), 1031-1041. DOI: 10.1016/0024-3205(91)90504-

Thomas, R. H., and Diggs, D. (2003). "Method of deacidifying cellulose-based materials," WO 2003044277 A2

Turbova, N. Y., Turevskaya, E. P., Kessler, V. G., and Yanovskaya, M. I. (2002). The Chemistry of Metal Alkoxides, Kluwer Adademic Publishers, Boston.

Urlaub, R., Posset, U., and Thull, R. (2000). "FT-IR spectroscopic investigations on solgel-derived coatings from acid-modified titanium alkoxides," J. Noncrystal. Solids 265(3), 276-284. DOI: 10.1016/S0022-3093(00)00003-X

Wächter, O., Ruhm, W., and Banik, G. (1998). "Verfarhren and Vorrichtung zur konservatorischen Behandlung von Papier," EP 0273902 A2.

Wagner, B., Bulska, E., and Sobucki, W. (2008). "Magnesium distribution in paper subjected to deacidification investigated by means of laser ablation inductively coupled plasma mass spectroscopy," Journal of Cultural Heritage 9(1), 60-65. DOI: 10.1016/j.culher.2007.11.001 
Wang, D.-G., Norwood, W., Alaee, M., Byer, J. D., and Brimble, S. (2013). "Review of recent advances in research on the toxicity, detection, occurrence, and fate of cyclic volatile methyl siloxanes in the environment," Chemosphere 93(5), 711-725. DOI: 10.1016/j.chemosphere.2012.10.041

Wedinger, R. S. (1993). “Mass cellulose deacidification process,” US Pat. 5,264,243.

Williams, J. C. (1971). "Chemistry of deacidification of paper," Bull. Am. Group IIC 12(1), 16-32. DOI: $10.2307 / 3178991$

Wilson, W. K., and Parks, E. J. (1979). "An analysis of the aging of paper: Possible reactions and their effects on measurable properties," Restaurator 3, 37-61. DOI: 10.1515/rest.1979.3.1-2.37

Wittekind, J. (1994a). "The Battelle mass deacidification process: A new method for deacidifying books and archival materials," Restaurator 15(4), 189-207. DOI: 10.1515/rest.1994.15.4.189

Wittekind, J. (1994b). "Solvents for agents to mass deacidify book and other paper products in an environmentally safe manner," German Pat. 3,904,111 A1; US Pat. $5,277,842$

Wittekind, J. (1996). "Process for restrengthening damaged paper and product produced thereby," US. Pat. 5,482,781.

Wittekind, J., Eggersdorfer, R., Schwerdt, P., Scherer, K.-H., and Schmitt, R.-E. (1994). "Neutralizing agent for paper products," US Pat. 5322558.

Wojciak, A. (2016). "Deacidification of paper with $\mathrm{Mg}(\mathrm{OH})_{2}$ nanoparticles: The impact of dosage on process effectiveness," Wood Res. 61(6), 937-950.

Worsfold, D. J. (1996). “Deacidification of cellulosic material," Can. Pat. 2142195.

Zervos, S. (2007). "Accelerated ageing kinetics of pure cellulose paper after washing, alkalization and impregnation with methylcellulose," Restaurator 28(1), 55-69. DOI: $10.1515 /$ rest.2007.55

Zervos, S., and Moropoulou, A. (2005). "Cotton cellulose ageing in sealed vessels. Kinetic model of autocatalytic depolymerization," Cellulose 12(5), 485-496. DOI: 10.1007/s10570-005-7131-7

Zitzmann, P., Leisch, N., and Kratzer, A. (2002). "Verfahren und Vorrichtung für Entsäueren Büchern," European Patent 1283300 A2; DE 10139517 A1.

Zweig, G., and Whitaker, J. R. (1967). Paper Chromatography and Electrophoresis, Academic Press, New York. 